\title{
Institutional design and spatial (in)equality - the Janus face of economic integration
}

by Ingrid Ott and Susanne Soretz

No. 142 | AUGUST 2020

\section{WORKING PAPER SERIES IN ECONOMICS}

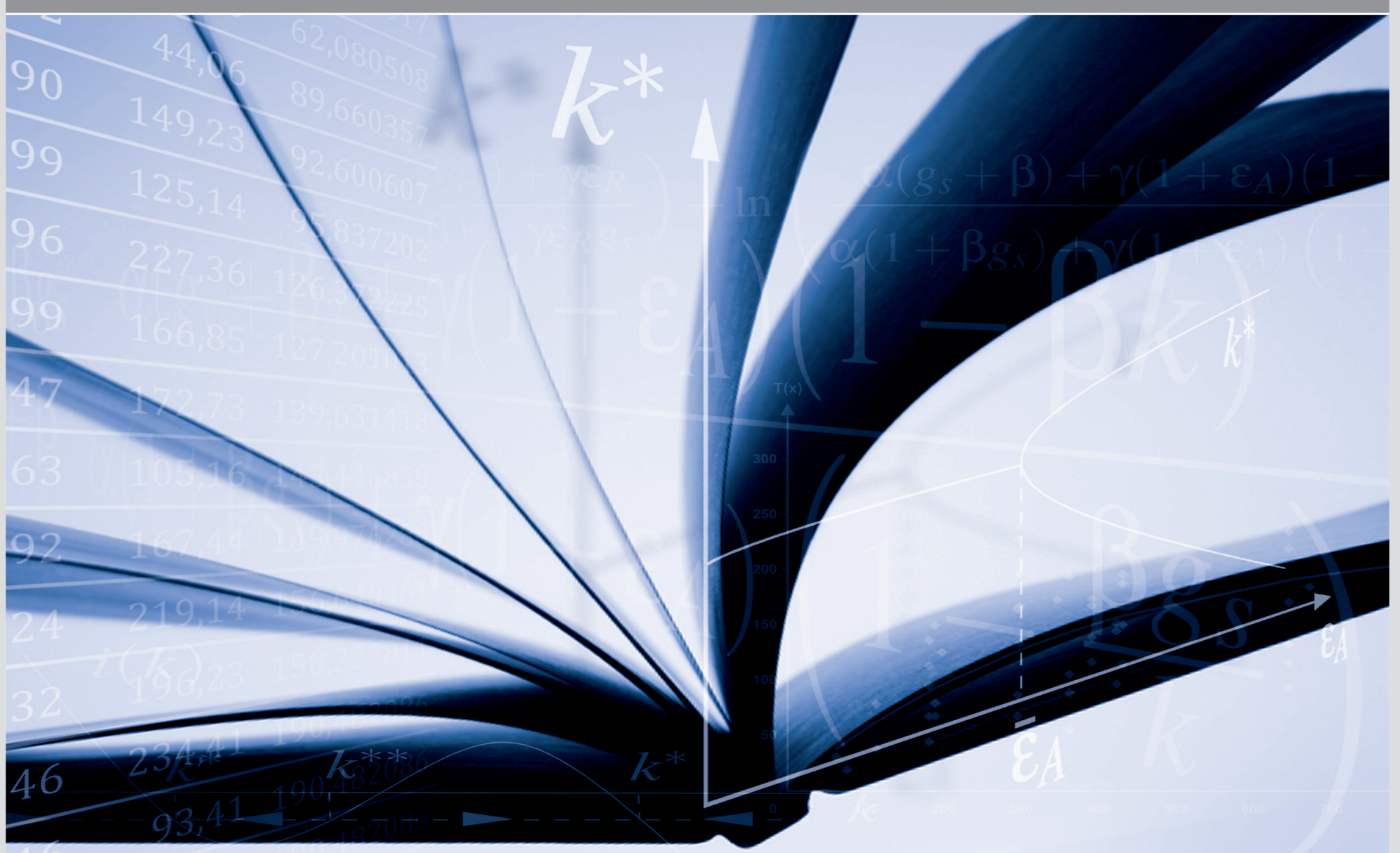




\section{Impressum}

Karlsruher Institut für Technologie (KIT)

Fakultät für Wirtschaftswissenschaften

Institut für Volkswirtschaftslehre (ECON)

Kaiserstraße 12

76131 Karlsruhe

KIT - Die Forschungsuniversität in der Helmholtz-Gemeinschaft

Working Paper Series in Economics

No. 142, August 2020

ISSN 2190-9806

econpapers.wiwi.kit.edu 


\title{
Institutional design and spatial (in)equality - the Janus face of economic integration
}

\author{
Ingrid Ott ${ }^{* \dagger}$ and Susanne Soretz ${ }^{\ddagger}$
}

August 4, 2020

\begin{abstract}
This paper analyzes within a spatial endogenous growth setting the impact of public policy coordination on agglomeration. Governments in each of the two symmetric regions provide a local public input that becomes globally effective due to integration. Micro-foundation of governmental behavior is based on three different coordination schemes: autarky, full or partial coordination. Scale effects act as agglomeration force and in addition to private capital agglomeration increase the concentration of the public input. Integration promotes dispersion forces with respect to the distribution of physical capital which are based on decreasing private returns. However, within the governments' decision on the concentration of the public input, increasing integration reinforces agglomeration because it promotes the interregional productive use of the public input. Taking feedback effects between the private and the public sector into account leads to mutual reinforcement, hence agglomeration forces almost always dominate and the spreading equilibrium becomes unstable. If convergence is a separate (additional) political objective, it needs sustained additional political effort.
\end{abstract}

Keywords: income convergence; integration; micro foundation of public policy; policy coordination; productive public input; multiple equilibria; bifurcation; spatial economic growth; stability of spatial equilibrium; global public input

JEL: H10, E60, O40, R50

\footnotetext{
*Karlsruhe Institute of Technology (KIT), Chair in Economic Policy, ingrid.ott@kit.edu

${ }^{\dagger}$ Kiel Institute for the World Economy (IfW)

${ }^{\ddagger}$ University of Greifswald, Chair in Growth, Structural Change and Trade; soretz@uni-greifswald.de
} 


\section{Motivation}

Reducing economic disparities has been a declared policy goal of the European Union (EU) since its founding treaties (compare Article 174 of the Treaty on the Functioning of the EU). The main instruments for achieving convergence include integration and (policy) coordination, and the EU also provides significant resources within the Structural and Cohesion Funds. Usually, per capita income is used as an indicator for determining (output)-convergence. Andersen et al. (2018) show that the EU has succeeded in approaching the convergence objective in the period 1995-2008 but since the sovereign debt and financial crisis economic divergence has again increased. However, what exactly coordination means and what the consequences of (lack of) coordination are for convergences is still poorly understood.

At a global level, sustained growth and ongoing spatial concentration of economic activity have been going hand in hand since the emergence of the industrial revolution. Today per capita income is higher in big cities, leading provinces and industrialized nations than in remote regions. This pattern holds almost independent from national and supranational policies. Naturally, public policies are designed to spur private sector activities. and to increase overall economic productivity. Productive public spending is then, alongside innovation or education, a major growth determinant, and the co-evolution of growth and spatial concentration is a natural outcome of market incentives and public policy.

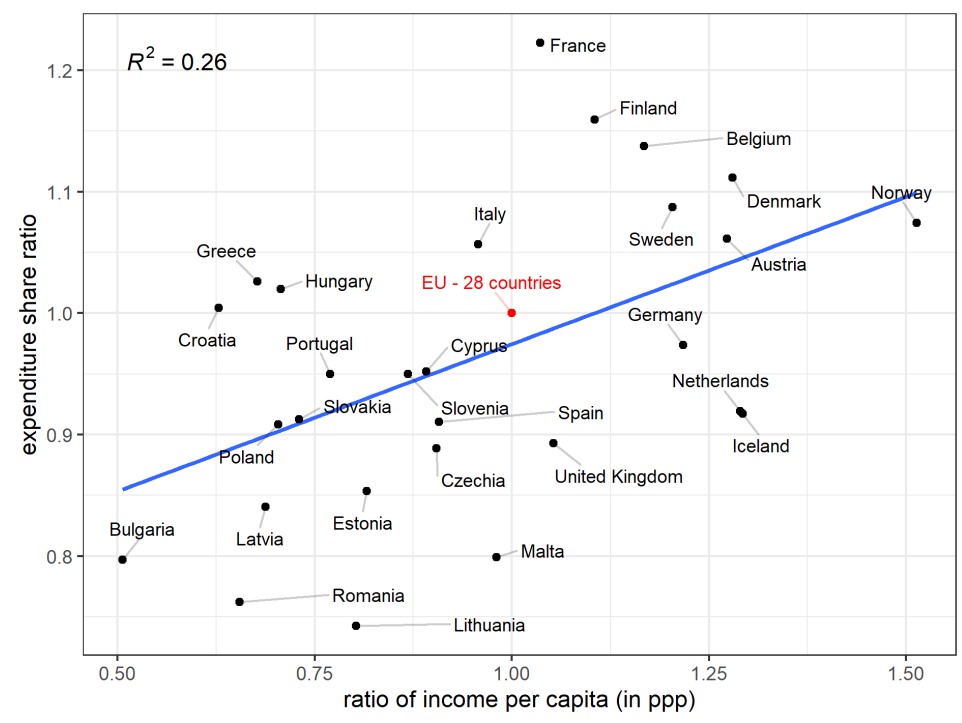

Figure 1: relationship between public and private sector activity as displayed by the ratios of income per capita and total general government expenditure share (EU28 average serves as benchmark to calculate the respective national position); EU28 countries without LUX and IRL, including Iceland and Norway; reference year: 20187; data from eurostat; own calculations.

A positive correlation between public expenditure and private production can be seen in Figure 1 which plots for the EU 28 states their relative position w.r.t. the EU 28 average both concerning income per capita (in ppas) and public expenditure, the latter referring to 'total general government expenditure'. Seen through this lens, private and public sector 
activity seem to act as complements which spur each other. Private investment is directed into regions which allow for the highest productivity and spatial concentration of economic activity is a natural outcome of market incentives (e.g. due to local increasing returns to scale). Integration in the sense of free and unhindered capital flows is a prerequisite for this to happen. As a consequence, existing disparities may be perpetuated or even increase thereby undermining the convergence goal.

Broken down by functions, however, it becomes clear that the positive correlation between private and public sector activity does not generally hold (compare Figure 2 for selected ). ${ }^{1}$ This requires a closer look at the type of public input provided.

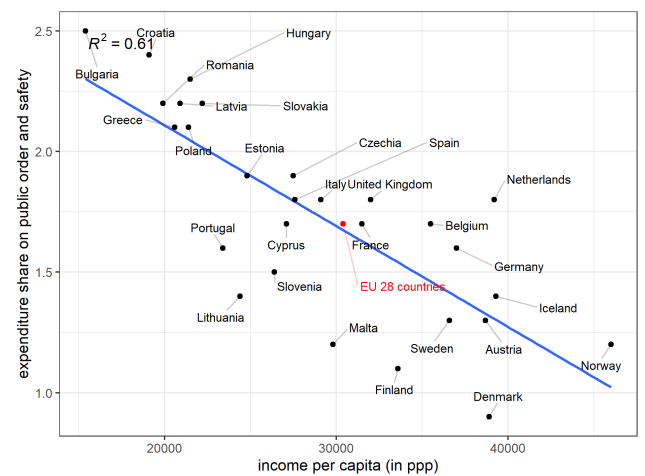

(a) public order and safety

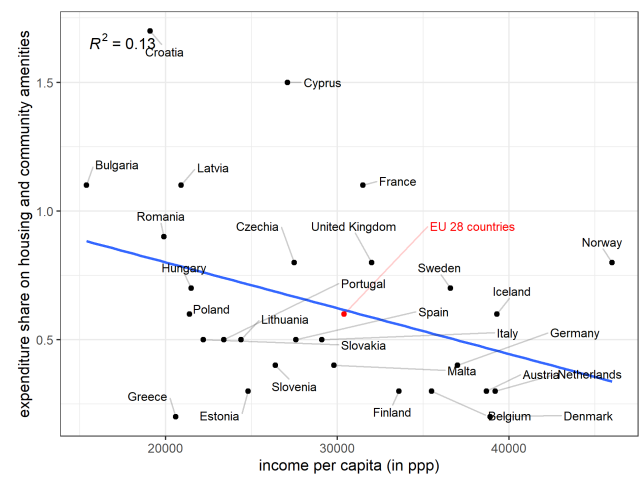

(c) housing and community amenities

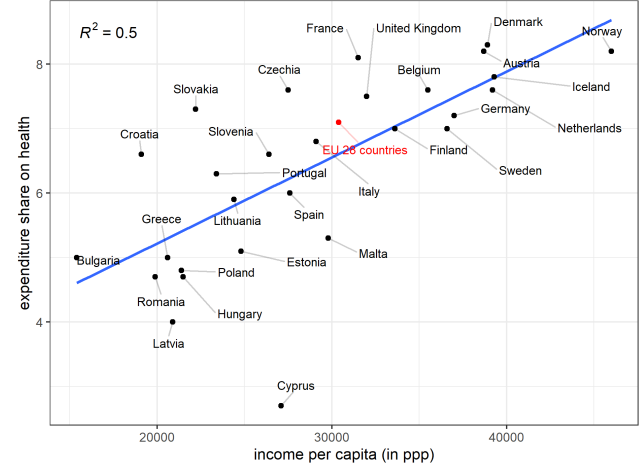

(b) health

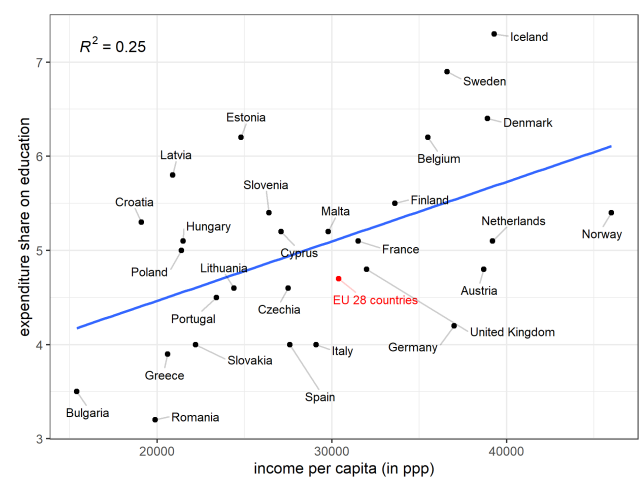

(d) education

Figure 2: 2018 public expenditure for selected functions and and income per capita in ppp (EU28 countries without LUX and IRL, including Iceland and Norway); data from eurostat; own calculations.

Within the funding peroid 2014-2022, the EU spends almost half of its budget (47\%) on only two programs, namely Economic, Social and Territorial Cohesion $(34 \% ; 371$ bn $€)$ and Competitiveness for Growth and Jobs (13\%; 142 bn €), (European Commission, 2020). This money is spent to enhance human well-being ('consumptive governmental expendi-

\footnotetext{
${ }^{1}$ Compare Appendix 9.1 for an overview on first and second order public expenditure associated to functions based on the classification of functions of government (COFOG) system.
} 
ture') and private sector productivity ('productive public expenditure'). The overall goal is to reduce regional economic disparities.

In addition to fiscal instruments, the EU also utilizes institutional economic policy instruments to pursue the convergence objective. Based on experience from the financial and sovereign debt crisis, the "European Semester" has been established by the European Commission in 2010. This framework is a consultation and coordination process between member states of the European institutions and targets in particular on the coordination of central macroeconomic policy areas. The associated policy coordination process aims to raise awareness of cross-border European implications of national policies.

Regarding converngece, all these facets will only be effective if the regions are connected in some way. There has been a long standing academic debate on the impact of integration on convergence. Integration is a prerequisite for transmission and spillovers across (administrative) borders. Related to this, the role of governmental tasks (functions) and the 'optimal' size of the state sector have been discussed.

Both, integration and coordination do not act isolated concerning convergence but also size and structure of public expenditure play important roles. Besides, when thinking about the equalization of living standards across nations one has to consider that convergence implicitly incorporates a spatial component. Additionally, local governments have to decide if and to which extent they want to coordinate their policies at a global level - be it expenditure or institutional rules. Related to this, especially the interregional transmission channels and how these interact in the context of private and public sector activity are of interest within the paper at hand.

These empirical observations together with the arguments provided before are the starting points of the paper at hand. Within the framework of a spatial growth model with productive government spending, we discuss the effects of different policy coordination schemes on the resulting [(un)equal] spatial distribution of economic activity - or in other words on convergence. Formally, and assuming full symmetry concerning factor endowment, technology and behavior of the private and public agents, the convergence goal could be understood as the realization of a spreading equilibrium in which individuals of any region have identical incomes. In doing so we extend the theoretical literature in several ways. Starting point is a two-region growth model with two local governments that provide a productive input which is complementary to private capital. Private individuals invest in the most productive region. Integration transforms the two local public inputs into a global public input which maybe accessed (at least partially) by the private individuals independent of the firm's location and opens up transmission channels. The implementation of a congestion function allows to differentiate the public input according to the functional classification of government expenditure with the idea to validate the model's implications on the basis of concrete data.

We interpret the coordination intensity of national expenditure policies as the extent to which transmission and spillover effects are taken into account by national policy-makers when deciding on state budgets. In analogy to the related theoretical literature, we interpret the term 'policy coordination' as a situation where - e.g due to well-designed incentives, institutional rules, or political agreements - the two countries move away from individual Nash policies to a joint policy that internalizes (at least some) cross-border externalities. Compared to isolated policy decisions, usually the outcome is then Pareto 
superior. In doing so we implement micro-foundation of two local governments and analyze how their strategies affect the distribution of economic activity in growing economies.

With regard to the convergence objective, we go beyond the mere analysis of its achievement. Formally put, we go beyond analyzing the existence of a spatial equilibrium which we define as a situation in which private individuals are indifferent as to the region in which investment will be realized. Instead, we are particularly interested in the stability properties of such a target and how it is influenced by different coordination schemes. These are not only driven by the respective setting, but especially by the interaction between private and public actors. In doing so we bridge the literature on public economics, growth theory, and New Economic Geography.

Our principal findings can be summarized as follows. First, not only the existence but especially uniqueness, stability characteristics and the resulting degree of spatial concentration incorporate important insights. Given full symmetry (concerning factor endowment and governmental behavior) spreading is always a resulting spatial equilibrium though the stability characteristics are ambiguous. In case of asymmetric public power (i.e. given partial coordination) a core-periphery structure results with the leading region representing the core. Other things being equal, convergence will never be achieved. Allowing for feedback effects between optimizing private and public agents has a destabilizing impact on the spatial equilibrium and these are the key driver of divergence. Put differently, stability characteristics of the spatial equilibrium change dramatically if feedback loops between private and public sector activity are taken into account. Second, not only the size but also the type of public expenditure is crucial for the resulting spatial equilibrium and its stability characteristics. Of special importance is the interplay of integration and coordination for convergence. The model allows for a differentiated understanding of the underlying cross-border transmission effects. Third, also from a technical perspective the model is interesting. Although the formal model framework is a neoclassical two-region growth model, the model type has central characteristics, which can also be found in models of New Economic Geography. These include multiple equilibria, cumulative causation and bifurcation. Therefore, the model is well suited to combine the various theory fields. Finally, our model is able to comply with empirical findings concerning governmental activity differentiated by functions and private sector activity. Against the background of the convergence objective, the result of our theoretical analysis is sobering. Convergence neither is a natural outcome of market forces nor can it be achieved in a setting where both public and private agents perpetually interact based upon optimization considerations. This holds for almost all coordination schemes and reasonable parameter constellations with the sole exception of very specific conditions: a public input with low scale effects, a high degree of integration and full coordination of national expenditure policies. One solution to this sobering results can be that for specified functions the governments commit themselves to a fixed budget. Given this, the declining marginal returns of further private capital accumulation have a stabilizing effect. In other words: the steady hand of the state is needed here.

The remainder of this paper is organized as follows. After presenting the theoretical framework in Section 3 we discuss the spatial distribution of the local public inputs for three different coordination schemes in Section 4. We derive the consequences for agglomeration in Section 5. Section 6 addresses the feedback effects between private and public decisions and their consequences for the spatial equilibrium. Section 7 summarizes and discusses 
the model's policy implications while Section 8 briefly concludes. Formal derivations are relegated to the appendix.

\section{Related literature}

The paper at hand relies on several key building blocks. The political and scientific discussion on spatial (in)equality is closely related to the convergence debate which addresses the relative welfare position of a country. From a perspective of growth theory, the two mostly employed concepts are the so-called $\beta$-convergence, which applies if poor countries tend to catch up to rich ones in terms of per capita income, while $\sigma$-convergence focuses on cross sectional comparisons (Barro and Sala-I-Martin (2004):chap. 11 for details on both concepts and more literature). The paper at hand maybe directly linked to the concept of $\beta$-convergence (Sala-I-Martin (1996a), Sala-I-Martin (1996b), Barro and Sala-I-Martin (1992), Chatterjee (2005) or more broadly Islam (2003)).

In political terms, the so-called convergence objective of the EU aims to establish equality of living conditions across all member states. Therefore, the EU has not only implemented the Maastricht criteria which are fundamental with regard to the common currency. In addition, the recent EU governance has established the European Semester as well as the Stability and Growth Pact as key instruments for economic and fiscal policy coordination. Related, Mortensen (2013) focuses on the distribution of power between various institutions, e.g. between the European Commission and the European Parliament. Recent overviews and assessments of the current state of EU convergence have been provided by European Commission (2017), Dolls et al. (2018), Andersen et al. (2018) or Franks et al. (2018).

The addressed policy coordination concepts lay ground for an analysis that focuses on the microfoundation of local government behavior in a spatial context. We discuss three different plicy coordination concepts that may be linked to the work of Hamada (1979) who analyzed within a game-theoretic context the interaction between national economic policy makers thereby contrasting non-cooperative Nash or Stackelberg outcomes with those achieved by cooperation (compare also Miller and Salmon (1985), Hamada and Kawai (1997) or McKibbin (1997) (empirical perspective) and the references therein). However, most of the literature on macroeconomic policy coordination focuses on exchange rates and monetary interdependence and thus on the associated implications of and for a monetary union. Just as old is the discussion about the necessity of a fiscal union, i.e. the establishment of a common European budget. Note that the discussion of the relationship between fiscal and monetary union is beyond the scope of the paper at hand.

Instead, we analyze the effects of different types of coordination of national budgets (allowing also for full coordination and hence a joint budget) on the associated public input (size and type) - and link these considerations to economic convergence. Related to this perspective, Ostry and Ghosh (2013):p. 4 point out that "Coordination works by allowing countries to improve the policy trade-offs they face under autarky". The authors also propose the implementation of a neutral assessor (one might think about a 'social planner') who may bridge divergent views of national policy makers and thereby internalizes at least some of the arising externalities coming along with public good provision. However, it should be noted that the effect of coordination cannot be seen independently of the 
depth of integration of the various countries. Key arguments of cross-border spillovers and / or cross-border transmission effects of policies are discussed by Benes et al. (2013) while Grüner (2013) raises potential problems related to not well-functioning coordination processes.

Other key issues of the paper at hand are the size of the public budget and its type, i.e. the way the budget is spent thereby addressing the use of government expenditure. Historical data on government expenditure has been provided e.g. by Lindert (1994). More data sources together with arguments related to government expenditure broken down by function, across countries and time can be accessed at Ortiz-Ospina and Roser (2020). They also point to two observations that appeared simultaneously across time and also worldwide: a continuously growing public sector size as well as a shift of funding priorities from defense (in war periods) to social security. Today, aside from social security funds, spendings on health and education dominate public expenditure in most OECD countries. Theoretically it is possible to derive the optimal size of the government based on efficiency considerations Barro (1990) points on the role of the expenditure share as a reasonable indicator. Farhad and Jetter (2019) propose an explanation of when and why (trade) openness may systematically affect the size of government. A differentiated perspective on the type of input can be captured theoretically via the application of a congestion function (compare Edwards (1990) ${ }^{2}$, Bradford, Malt, and Oates (1996), Eicher and Turnovsky (2000) or more closely related to geographical economics Henderson (1974), Brakman et al. (1996) or more recently Hirte, Lessmann, and Seidel (2020)). Empirically, this is represented by a breakdown of government expenditure by functions they perform. ${ }^{3}$ The different functions mirror "the main priorities and challenges of governments. [...] Also common goals set by regional agreements (such as OECD-EU countries) on energy, infrastructure and research and development programs are all reflected in the structure of government's expenditure." (OECD (2015a):p. 72).

To better understand the spatial distribution of economic activity and the emergence of core-periphery structures is the key concern of the New Economic Geography (recent overviews based on the work of Krugman $(1991,1995)$ are provided by Fujita, Krugman, and Venables (2001), Brakman, Garretsen, and Marrewijk (2009) and several contributions in the Handbook of Regional Science (Fischer and Nijkamp, 2014)). Within this literature, only few papers focus on public activity in the context of regional inequality and if so, they implement transport cost reducing infrastructure (among them Martin and Rogers (1995) or Brakman, Garretsen, and Marrewijk (2002)). The public input then unequivocally reinforces regional inequality. One exception is Puga (2002) who highlights that the provision of a productive input might even act as dispersion force given certain characteristics of the public input and integrated regions. Important characteristics of the New Economic Ge-

\footnotetext{
${ }^{2}$ He proposes to consider the non-public nature of a local public good.

${ }^{3}$ See Appendix 9.1 or e.g. Annex C in OECD (2015b) which provides an overview of first- and secondlevel classification of functions of governments (COFOG). The academic literature differentiates between productive expenditure (sum of expenditure on education, health, defense, housing and community amenities, economic affairs, general public services - which aim to enhance private sector productivity) and non-productive government expenditure (sum of expenditure on public order and safety, recreation and social protection - which focus on individual well-being), compare Adam and Bevan (2005), Bleaney, Gemmell, and Kneller (2001), Park (2006), Christie (2012) or Gemmell, Kneller, and Sanz (2016). However, we argue that public order and safety also have productivity impact which is especially important in the context of foreign direct investment.
} 
ography's core model are cumulative causation, the possibility of multiple equilibria with ambiguous stability characteristics and the potential to be non-optimal. Finally, there is interaction of agglomeration and trade flows. Key drivers that shape the economic landscape are imperfect competition, increasing returns, and transportation costs. Spatial inequality is then the natural outcome of efficiency consideration of optimizing private individuals. A broader discussion of the role of regional institutions have been provided e.g. by Deeken and Ott (2014) or Brakman, Garretsen, and Marrewijk (2009):pp. 461-470.

These building blocks are the basis for the mode lat hand. Within a two-country growth model we investigate how the provision of productive public expenditure affects the emergence and the stability characteristics of the spatial equilibrium for three different policy coordination schemes.

\section{Theoretical framework}

We assume a two region setting populated by private individuals and governments that provide local public inputs. ${ }^{4}$ Firms in the symmetric regions produce the homogenous final good, $Y_{i}$, according to the production function

$$
Y_{i}=L_{i}^{\lambda} K_{i}^{\alpha} D_{i}^{\gamma}, \quad 0<\lambda, \alpha, \gamma<1, \quad i=1,2
$$

with $L_{i}$ as immobile labor and $K_{i}$ as physical capital in region $i$. The global public input, $D_{i}$, covers access to both regional public inputs, $G_{s i}$, and is modeled as

$$
\begin{aligned}
& D_{1}=G_{s 1}+\beta G_{s 2} \\
& D_{2}=G_{s 2}+\beta G_{s 1}
\end{aligned}
$$

The degree of integration between the two regions is parameterized by $\beta \in[0,1] .^{5}$ It may be interpreted as the extent to which the two local public inputs become globally effective: If $\beta=0$, firms in each region only utilize the public input provided by their local governments. In contrast, $\beta>0$ implies that firms in one region also have (partial) access to the other region's public input. For a broad specification of the public input, integration may e.g. be interpreted as increasing the flows of ideas between two regions, as connecting national physical infrastructure networks, the recognition of foreign degrees or joint defense (e.g. Rivera-Batiz and Romer (1991) argue similarly).

We specify the regional public input analogous to the congestion function concept introduced by Edwards (1990) and adopted by Eicher and Turnovsky (2000). It may be associated with various types of congestion and scale such that the services that an individual firm gets out of the utilization is specific to the public input. Being more precise, the services derived by the individual firm in region $i$ from government expenditure in the same region are represented by

$$
G_{s i}=G_{i}\left(\frac{K_{i}}{\bar{K}_{i}}\right)^{\varepsilon_{R}} \bar{K}_{i}^{\varepsilon_{A}}, \quad 0 \leq \varepsilon_{R} \leq 1, \quad-\alpha \leq \varepsilon_{A} \leq 1
$$

\footnotetext{
${ }^{4}$ Compare Barro (1990) for the baseline model in a one region context.

${ }^{5}$ Note that in some simulations the domain of $\beta$ is restricted to $\beta \in(0,1)$ for technical reasons.
} 
where $\bar{K}_{i}$ denotes the aggregate stock of private capital, and analogously $G_{i}$ denotes the aggregate flow of government expenditure. ${ }^{6}$ We assume non-distortionary financing of the public expenditure, the absence of interregional transfers and in each period a balanced public budget. ${ }^{7}$

The congestion function (3) incorporates the potential for the regional public good to be associated with alternative degrees of absolute congestion, denoted by $\varepsilon_{A}$, or relative congestion, denoted by $\varepsilon_{R}$. Concerning relative congestion, $\varepsilon_{R}$, the usual interpretation applies. It measures the degree of rivalry arising in the utilization of the public input: $\varepsilon_{R}=0$ specifies a public input that is available as pure public good (e.g. an empty and tollfree road) whereas the other polar case, $\varepsilon_{R}=1$, implies that each firm only benefits from $1 / N$ parts of the public input with $N$ denoting the number of firms. ${ }^{8}$ This specification of the congestion function also allows to link the model (via $\varepsilon_{A}$ ) to empirical data on governmental activity as captured within the COFOG classification and discussed in the introduction of this paper.

Since in equilibrium $\bar{K}_{i}=N_{i} K_{i}$ applies

$$
g_{s}=g k^{\varepsilon_{A}} n^{\varepsilon_{A}-\varepsilon_{R}}
$$

defines the equilibrium ratio of governmental activity $g_{s} \equiv \frac{G_{s 1}}{G_{s 2}}$, with $k \equiv \frac{K_{1}}{K_{2}}, g=\frac{G_{1}}{G_{2}}$ and $n \equiv \frac{N_{1}}{N_{2}}$.

We extend the congestion function specification of Eicher and Turnovsky (2000) such that we do not restrict the sign of $\varepsilon_{A}$, to be negative, but also allow for positive values. This allows linking our perspective to the interpretation of spillovers as developed by Romer (1986) while negative values of $\varepsilon_{A}$ may be associated to public inputs which have a strong local public impact (such as e.g. public order and safety or community and housing amenities). The productivity effects from the public input are related to the size of the private sector as measured by the aggregate private capital stock, $\bar{K}$.

The interpretation of $\varepsilon_{A}$ may be associated with its sign. For $\varepsilon_{A}<0$, the well recognized absolute congestion applies. The associated logic is that rivalry w.r.t. the public input reduces private capital productivity. The effect of negative $\varepsilon_{A}$, absolute congestion, in this sense is rather similar to the one of relative congestion. In contrast, $\varepsilon_{A}>0$ includes arguments of endogenous growth as established by Romer (1986). Other things being equal, private capital returns are higher in case of a positive $\varepsilon_{A}$. In the following we call the associated impact scale effects. As will be shown subsequently, scale effects are a crucial determinant of agglomeration.

We apply the usual assumption that governments set the aggregate expenditure levels,

\footnotetext{
${ }^{6}$ Allowing for balanced growth requires that the condition $\alpha+\varepsilon_{A} \geq 0$ has to be satisfied. It results from the knife-edge assumption $\alpha+\gamma\left(1+\varepsilon_{A}\right)=1$ that has to be met to allow for equilibrium endogenous growth. The formal setup of the underlying growth model is presented in Appendix 9.4.

${ }^{7}$ Note that this implies symmetrically balanced budgets. Ott and Soretz (2010) briefly discuss the impact of distortionary income taxes within a two-region baseline model.

${ }^{8}$ Notice that throughout the discussion of this paper we focus on the implications of scale, $\varepsilon_{A}$, and integration, $\beta$, thereby assuming a certain degree of relative congestion $\bar{\varepsilon}_{R}>0$ in order to confine the input from a pure public good that is characterized by the absence of rivalry.
} 
$G_{i}$, as a constant fraction, $\Theta_{i}$, of aggregate capital, $\bar{K}_{i}$, such that ${ }^{9}$

$$
G_{i}=\Theta_{i} \bar{K}_{i}, \quad 0<\Theta_{i}<1
$$

An expansion in government expenditure is then parameterized by an increase in the capital share, $\Theta_{i}$. Together with 4,

$$
g_{s}=\theta k^{1+\varepsilon_{A}} n^{1+\varepsilon_{A}-\varepsilon_{R}}
$$

defines the equilibrium ratio of governmental activity, with $\theta \equiv \frac{\Theta_{1}}{\Theta_{2}}$. This ratio together with the specification of $D_{i}$ from (2) are key and provide the basis for rich interdependencies between the private sector (as embedded in private capital, $k$ ) and the public sector (as especially captured by public capital, $\theta$, scale, $\varepsilon_{A}$, and integration, $\beta$ ). Utilizing equations (2)-(6), production from equation (1) may be rewritten in relative form as ${ }^{10}$

$$
y=k^{\alpha} l^{\lambda}\left(\frac{g_{s}+\beta}{1+\beta g_{s}}\right)^{\gamma}
$$

with $y \equiv \frac{Y_{1}}{Y_{2}}$ and $l \equiv \frac{L_{1}}{L_{2}}$.

Our spatial equilibrium concept is based on private and public optimization decisions. In Section 4, the governments optimize for a given distribution of private capital, formally $\theta(k)$. In Section 5, the private individuals optimize for a given distribution of the public input, formally $k(\theta)$. Within Section 6 , these two perspectives are merged such that the resulting equilibrium involves mutual interaction between the private and the public optimization decisions.

\section{Strategic governmental behavior}

In this section, we analyse the the local government's decision on the amount of the local public input and show that relative governmental activity is driven by private capital distribution, $\theta=\theta(k)$. Due to integration, any local government's decision also affects the global public input, $D_{i}$. As a consequence, regional public decisions become globally effective regarding private capital productivity and thus drive private investment incentives. Efficiency considerations require to equalize marginal productivity and unit marginal costs of providing the public input. While marginal costs for the public input are easy to determine, marginal productivity in a two-region setting is affected by various factors, among them the degree of integration, the type of the input as modeled via the congestion parameters $\varepsilon_{A}$ and $\varepsilon_{R}$, thereby reflecting e.g. spendings for infrastructure, health, education, or housing and community amenities. ${ }^{11}$

The coordination schemes discussed below imply different public decision rules, and these are key to the resulting spatial distribution of economic activity. The following

\footnotetext{
${ }^{9}$ Note that this is in line with considering the expenditure share or the stylized fact of Kaldor (1961) of a constant capital coefficient.

${ }^{10}$ The relative perspective immediately allows to identify spatial concentration in region 1 if the value of the considered factor exceeds unity.

${ }^{11}$ Note that the public input is modeled as a flow. We thereby follow Barro (1990) who imposes the public efficiency condition $d Y / d G=1$ representing the assumption that one unit of output can be transformed costlessly into one unit of capital or into expenditure for the public input.
} 
arguments come into play. First, global production amounts to $Y=Y_{1}+Y_{2}$, but the local governments do not necessarily focus on aggregate but rather on local output. Second, there are two governments that decide upon the provision of the respective local public input. Basically, since both local public inputs imply the same cost, local public expenditure might be exchanged for each other, $G=G_{1}+G_{2}$. We show that, although this relationship generally holds, the way it is considered in decisions of the local governments is crucially affected by the underlying coordination scheme. Third, there are interregional transmission effects due to integration. The decision of a region on the local public input affects capital productivity - and thus private investment incentives - also in the respective other region. Besides, integration allows for shifting productivity between the regions.

From a firm's perspective in e.g. region 1 the 'global' public input is given by $D_{1}=$ $G_{s 1}+\beta G_{s 2}$, which implies that integration, scale, and congestion interact. Therefore, the decision about where to install the 'local' public input becomes a non-trivial task for the governments and may serve as a basis for strategic behavior.

Starting point to analyze the institutional impact is whether and to which extent these various relationships and feedback effects are taken into account by the local governments. The following coordination schemes of the two governments will be addressed:

1. full coordination: this setting assumes joint decision of both governments thereby taking the actually existing regional interdependencies into account. The focus is on joint output $\left(Y=Y_{1}+Y_{2}\right)$, and both governments correctly recognize that local public expenditure may perfectly substitute for each other $\left(G=G_{1}+G_{2}\right)$ such that $d G_{1}=-d G_{2}$ applies. In this setting, local public investments will be allocated as to equalize productivities of the local public inputs thereby considering aggregate production, $Y$ (compare (8)).

2. no coordination: this setting assumes that, although there are interregional economic interdependencies, the other region's policy is treated as being exogenous to the decisions of an optimizing local public agent. This implies that the two public inputs are not considered as potential substitutes, and the focus of each government is on local output, $Y_{1}$ and $Y_{2}$, only (compare (15)). Consequently, the provision of a public input in one region becomes an externality for the other region's government.

3. partial coordination: this setting assumes a leading and a following region. The leading region's politician is quite aware of the decisions of the (myopic) follower region that just optimizes as in case of no coordination. Again, only local output $Y_{1}$ and $Y_{2}$ is addressed by each region independently (compare (20)-(22)). The interdependencies between the two local public inputs are in part being internalized by the leader - though not with the intent to maximize welfare but own interest of the leading region.

It will be shown that independent of the chosen coordination scheme, the spatial equilibrium is shaped by the interaction of three effects: a positive complementarity effect, a negative substitution effect and an ambiguous integration effect. However, depending upon the coordination scheme, differences in the optimal expenditure share ratios result. 


\subsection{Full coordination}

Full coordination is equivalent to the perspective of a benevolent social planner. The associated public efficiency condition in case of fully coordinated public policies assumes that the regional governments simultaneously focus on aggregate output, $Y=Y_{1}+Y_{2}$, and aggregate public expenditure, $G=G_{1}+G_{2}$. Formally, the efficiency condition transforms to

$$
\frac{d Y}{d \theta}=\frac{\partial Y}{\partial G_{1}} \frac{\partial G_{1}}{\partial \theta}+\frac{\partial Y}{\partial G_{2}} \frac{\partial G_{2}}{\partial \theta} \stackrel{!}{=} 0
$$

Shifting public expenditure between the two regions implies $d G_{1}=-d G_{2}$ while equalizing marginal costs to marginal productivity is given by $\frac{\partial Y}{\partial G_{1}}=\frac{\partial Y}{\partial G_{2}}=1$. For the production technology from eqs. (1)-(3), marginal productivities of the two local public inputs are given by

$$
\begin{aligned}
\frac{\partial Y}{\partial G_{1}} & =\gamma \frac{Y_{1}}{D_{1}} N_{1}^{\varepsilon_{A}-\varepsilon_{R}} K_{1}^{\varepsilon_{A}}+\beta \gamma \frac{Y_{2}}{D_{2}} N_{1}^{\varepsilon_{A}-\varepsilon_{R}} K_{1}^{\varepsilon_{A}} \\
\frac{\partial Y}{\partial G_{2}} & =\beta \gamma \frac{Y_{1}}{D_{1}} N_{2}^{\varepsilon_{A}-\varepsilon_{R}} K_{2}^{\varepsilon_{A}}+\gamma \frac{Y_{2}}{D_{2}} N_{2}^{\varepsilon_{A}-\varepsilon_{R}} K_{2}^{\varepsilon_{A}}
\end{aligned}
$$

Replacing them into efficiency condition (8) and utilizing proportionality according to (5) provides $G_{1}=\theta n k G_{2}$. This implies $\frac{d G_{1}}{d \theta}=n k G_{2}$ and $-\frac{d G_{2}}{d \theta}=n k G_{2}$, and one obtains the key condition describing fully coordinated policies:

$$
\left(\frac{g_{s}+\beta}{1+\beta g_{s}}\right)^{\gamma-1}=\frac{1-\beta k^{\varepsilon_{A}} n^{\varepsilon_{A}-\varepsilon_{R}}}{k^{\varepsilon_{A}} n^{\varepsilon_{A}-\varepsilon_{R}}-\beta} l^{-\lambda} k^{-\alpha}
$$

This relationship determines the size of the public input ratio $\theta^{*}$ implicitly. The explicit representation of $\theta^{*}$ may be derived by utilizing equations (3), (6) and solving (10) for $\theta$

$$
\begin{aligned}
& \theta^{*}\left(k, \varepsilon_{A}, \beta, \ldots\right)=\frac{\Psi-\beta}{(1-\Psi \beta) \Upsilon} \\
& \quad \text { with } \Psi \equiv\left(\frac{k^{\alpha} l^{\lambda}\left(k^{\varepsilon_{A}} n^{\varepsilon_{A}-\varepsilon_{R}}-\beta\right)}{1-\beta k^{\varepsilon_{A}} n^{\varepsilon_{A}-\varepsilon_{R}}}\right)^{\frac{1}{1-\gamma}}, \quad \Upsilon \equiv k^{1+\varepsilon_{A}} n^{1+\varepsilon_{A}-\varepsilon_{R}}
\end{aligned}
$$

Figures $3(\mathrm{a})-3(\mathrm{c})$ plot $\theta^{*}(k)$ for selected parameter constellations of scale $\left(\varepsilon_{A}\right)$ and integration $(\beta) .{ }^{12}$

If the regions are symmetric $(l=n=1)$, the right hand side in (10) equals unity. The spreading equilibrium applies and independent of scale and integration, $\theta^{*}=k=1$ results: Using (6), the optimality condition (10) reduces to

$$
\frac{g_{s}+\beta}{1+\beta g_{s}}=1 \quad \Rightarrow \quad g_{s}=1 \quad \Rightarrow \quad \theta^{*}(k)=1
$$

In the spreading equilibrium, efficient government expenditures will also be equally distributed across the two regions (compare the intersection of the dashed and the solid function in Figures 3(a)-3(c)).

\footnotetext{
${ }^{12}$ Notice that in Figure 3(c) the negative value $\varepsilon_{A}=-0.05$ has been chosen to illustrate that the positive slope of the functions $\theta^{*}(k)$ is not linked to the sign of the scale parameter. Instead, the interaction between integration and scale are decisive. For $\varepsilon_{A}>0$ the slope of $\theta(k)$ is unequivocally positive.
} 


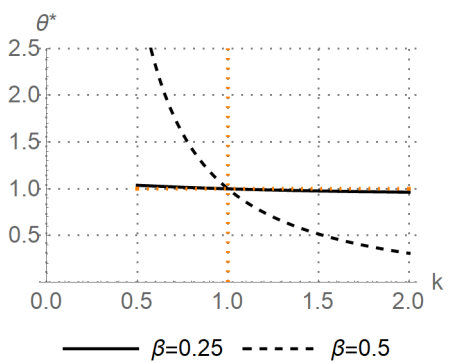

(a) $\varepsilon_{A}=-0.2$ : negative effect dominates, $\frac{d \theta^{*}}{d k}<0$

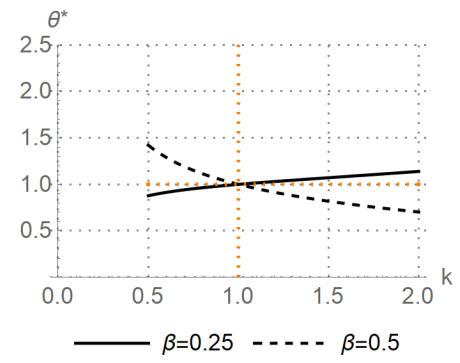

(b) $\varepsilon_{A}=-0.15:$ total effect is ambiguous, $\frac{d \theta^{*}}{d k} \gtrless 0$

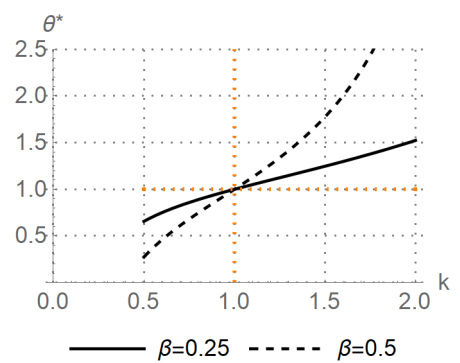

(c) $\varepsilon_{A}=-0.05:$ positive effect dominates, $\frac{d \theta^{*}}{d k}>0$

Figure 3: $\theta^{*}\left(k, \ldots \varepsilon_{A}, \beta \ldots\right)$ based on equation (11) for selected values of integration and scale; other parameters: $l=1, n=1$ (which implies no impact of $\varepsilon_{R}$ ), $\alpha=0.5$.

Now we are prepared to focus on the more realistic case that private capital is unequally spread across regions. In the following, we will define the region with the larger capital stock to be region 1 , hence unequal capital distribution is equivalent to $k>1$. Jointly optimizing governments will adjust the ratio $\theta^{*}$ based on three major effects which will be explained below. In order to calculate the adjustment in $\theta^{*}$, one has to notice that both $g_{s}$ at the left hand side as well as the term on the right hand side in (10) are functions of the capital distribution $k$. Utilizing the implicit function theorem, this adjustment can be described by ${ }^{13}$

$$
\begin{aligned}
\frac{d \theta^{*}}{d k}= & \frac{1-\beta n^{\varepsilon_{A}-\varepsilon_{R}} k^{\varepsilon_{A}}}{n^{\varepsilon_{A}-\varepsilon_{R}} k^{\varepsilon_{A}}-\beta} \frac{\alpha l^{-\lambda} k^{-\alpha}\left(g_{s}+\beta\right)^{2-\gamma} \theta^{*} / k^{2}}{\left(1+\beta g_{s}\right)^{-\gamma}(1-\gamma)\left(1-\beta^{2}\right) g_{s}} \\
& +\frac{n^{\varepsilon_{A}-\varepsilon_{R}} \varepsilon_{A} k^{\varepsilon_{A}-1}\left(1-\beta^{2}\right)}{\left(n^{\varepsilon_{A}-\varepsilon_{R}} k^{\varepsilon_{A}}-\beta\right)^{2}} \frac{l^{-\lambda} k^{-\alpha}\left(g_{s}+\beta\right)^{2-\gamma} \theta^{*} / k}{\left(1+\beta g_{s}\right)^{-\gamma}(1-\gamma)\left(1-\beta^{2}\right) g_{s}} \\
& -\left(1+\varepsilon_{A}\right) \frac{\theta^{*}}{k} \gtrless 0
\end{aligned}
$$

The sign of (14) and thus the reaction of public activity across space on concentrated private capital distribution is indeterminate (compare Figures 3 and 4).

If private economic activity is concentrated, $k>1$, optimal public activity will also be concentrated though not necessarily in the bigger region 1 . For sufficiently low $\varepsilon_{A}$ (compare Figure 3(a)), the negative effects incorporated in equation (14) dominate such that private activity in the larger region substitutes for public activity. Put differently, in order to dampen productivity losses due to negative scale of the public input, public expenditure is shifted from the larger to the smaller region. As a consequence $\theta^{*}$ declines as $k$ increases. This negative effect is reinforced by integration (compare dashed line). For sufficiently high (though not necessarily positive) levels of scale, the positive effects in (14) dominate and $\theta^{*}$ increases in $k$. Scale effects in the public input increase productivity in the larger region, hence public expenditure is redirected from the smaller to the larger region. Again, integration reinforces this relationship (compare Figure 3(c)). For intermediate levels of

\footnotetext{
${ }^{13}$ For a formal derivation of the total effect broken down by the three partial effects (complementarity, substitution, integration), compare Section 9.3.1 in the Appendix.
} 
scale (compare Figure 3(b)), however, integration has an ambiguous impact: other things being equal, reducing the degree of integration then turns the dominance of the negative effects to a dominance of the positive effects.

The total effect within (14) originates from three different sources that describe the relationships between $g_{s}, \theta$ and $k$ :

First, a positive complementarity effect arises between $\theta$ and $k$, given in the first line of equation (14). If the private capital distribution is concentrated (i.e. for $k>1$ ), productivity of the public input increases relatively more in the larger region due to the better endowment with physical capital and the complementarity of private and public capital. Other things being equal, expenditure for the public input will be shifted towards the larger region in order to equalize the marginal productivities of the two local public inputs. As a consequence, the distribution of the public input becomes more concentrated as well, $\theta^{*}$ increases. To give an example, in the metropolitan area, there is more need for infrastructure, hence the associated government share should be higher in the larger region.

Second, there is a negative substitution effect between $\theta$ and $k$, given in the third line of equation (14). Due to proportionality (remember equation (5)), the actually available amount of the public input, $G_{s}$, is larger in the region with higher aggregate capital. Consequently, for any expenditure share, $\theta$, the concentration of the public input, $g_{s}$, increases with $k>1$ (compare (6)). In order to obtain a certain level of governmental services, private capital may be reduced reacting on the increase in public input. Put differently, stronger concentration of the public input (higher $\theta$ ) c. p. induces a negative substitution effect on the concentration of the private input and vice versa. As can be seen in the second line equation (14), this effect is independent of integration, $\beta$, whereas its strength size unequivocally increases with the value of $\varepsilon_{A}$.

Third, there are ambiguous effects due to integration, given in the second line of equation (14). The integration effect captures the governments' awareness of the possibility to shift public expenditure back and forth between the two regions. The sign of $\varepsilon_{A}$ determines the direction of the integration effect: If scale effects are positive, $\varepsilon_{A}>0$, any increase in $k$ augments the effective amount of the public input in the larger region. ${ }^{14}$ Integration provides (partial) access also to the remote public input and allows for interregional substitution between local public expenditures. To enable private firms to benefit from the scale effects, government expenditure is shifted from the smaller to the larger region - and the resulting productivity impact is then taken back to the 'home' region via integration. Other things being equal, $\theta^{*}$ increases. Contrariwise, if congestion in the sense of negative scale effects applies, i.e. if $\varepsilon_{A}<0$, an increase in $k$ reduces the effective amount of the public input in the larger region. A shift of government expenditures from the larger to the smaller region then lowers the scale disadvantage and results in a decrease in $\theta^{*}{ }^{15}$

For the the spreading equilibrium, $k=1$, visual representations of the partial effects can be seen in Figures 4 for alternative combinations of $\beta \in(0,1)$ (vertical axis) and $\varepsilon_{A} \in(-0.4,1)$ (horizontal axis). For the mentioned parameter settings, the strength

\footnotetext{
${ }^{14}$ Formally, this can be derived by introducing the equilibrium condition $\bar{K}_{i} \equiv N_{i} K_{i}$ into (3) which then reduces to $G_{s i}=G_{i} N_{i}^{\varepsilon_{A}-\varepsilon_{R}} K_{i}^{\varepsilon_{A}}$.

${ }^{15}$ Notice that the sign of $\varepsilon_{A}$ determines the direction of the integration effect only but not necessarily the sign of the total effect.
} 


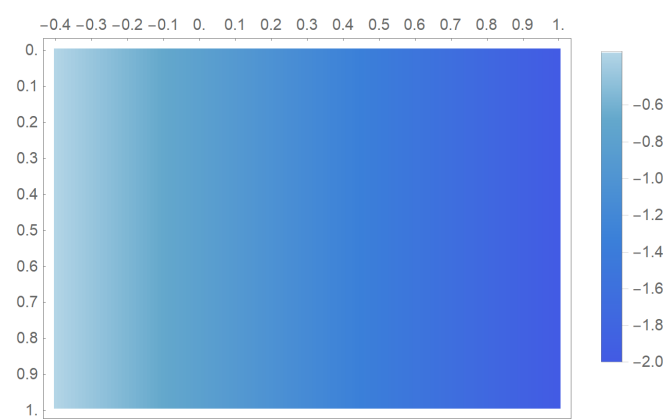

(a) negative substitution effect

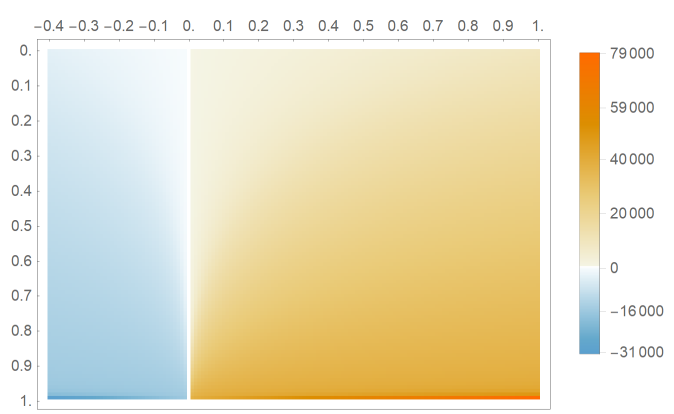

(c) ambiguous integration effect

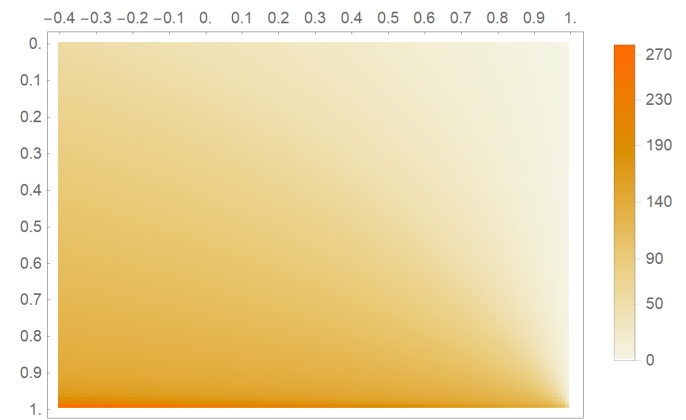

(b) positive complementarity effect

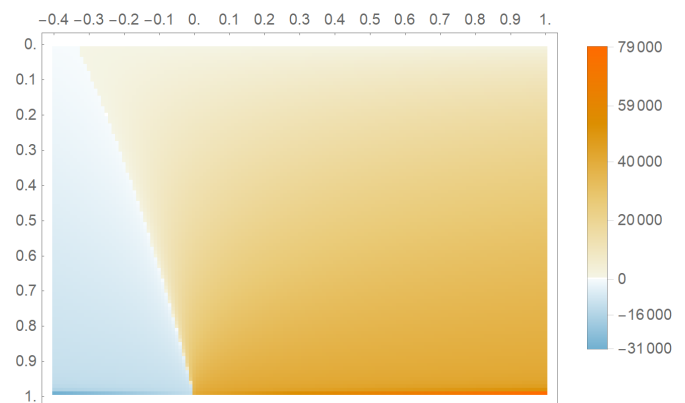

(d) ambiguous total effect

Figure 4: $d \theta^{*}\left(k, \ldots \varepsilon_{A}, \beta \ldots\right) / d k$ from (14) for $k=1$; three partial effects and ambiguous total effect in case of full coordination depending upon integration (vertical axis) and scale (horizontal axis); total effect is sum of three partial effects; horizontal axis: $\varepsilon_{A} \in(-0.4,1)$; vertical axis: $\beta \in(0,1)$, other parameters: $l=1, n=1$ (which implies no impact of $\varepsilon_{R}$ if $n=1$ ), $\alpha=0.5$; plots are based on equations (42)-(44); colorbars document effect strength (color intensity) and sign (blue: negative; red: positive).

of each effect and its sign is documented in the colorbars. Notice the ambiguity of the integration effect: for $\varepsilon_{A}>0$ it strengthens the positive complementarity effect, whereas $\varepsilon_{A}<0$ reinforces the negative substitution effect. Concerning the substitution effect, for given values of $\varepsilon_{A}$, the degree of integration does not matter.

The sign of the total effect of $d \theta^{*} / d k$ depends upon the interaction of the three partial effects. It is ambiguous in case of full coordination and crucially driven by the strong integration effect. If congestion applies $\left(\varepsilon_{A}<0\right)$, the integration effect is negative: increasing concentration of private capital, $k$, reduces the productivity of public services in the larger region and induces a shift of public expenditures towards the smaller region. This shift is more pronounced in case of stronger integration (higher $\beta$ ) since the larger region can benefit more easily from the public services provided in the smaller region. Hence, a negative total effect will results for high values of integration and low values of $\varepsilon_{A}$.

Contrariwise if scale effects apply $\left(\varepsilon_{A}>0\right)$, the integration effect is positive: increasing concentration of private capital in this case enhances the productivity of public services in the larger region. Public efficiency requires a shift of public expenditure towards the larger region and the shift again will be more distinct in case of high values of integration.

To sum up, agglomeration will be reinforced by governmental decisions whenever the 
total effect is positive, hence predominantly for scale effects and strong integration. If instead the public input is characterised by absolute congestion (and again integration is strong enough) such that the total effect is negative, governmental decisions reduce concentration and and result in a dispersion force.

As will be shown in the two subsequent Sections 4.2 and 4.3, all three effects also hold for partial and no coordination though to different extents. As a consequence, the resulting total effects also differ between the coordination schemes.

\subsection{No coordination}

If each region decides autarkic on the level of own public expenditure, the local governments consider the public input of the respective other region as exogenous factor such that the option to exchange between local public expenditure is neglected, $-d G_{1} / d G_{2}=0$. The same applies concerning the contribution of local output, $Y_{i}$, to aggregate output, $Y$. Autarkic local optimization assumes regionally disconnected efficiency considerations that amount to equalizing the marginal productivities of the local public inputs independently. Efficieny considerations of autarkic governments require ${ }^{16}$

$$
\frac{\partial Y_{1}}{\partial G_{1}}=1 \quad \text { and } \quad \frac{\partial Y_{2}}{\partial G_{2}}=1
$$

with the marginal products given by ${ }^{17}$

$$
\begin{aligned}
& \frac{\partial Y_{1}}{\partial G_{1}}=\gamma \frac{Y_{1}}{D_{1}} N_{1}^{\varepsilon_{A}-\varepsilon_{R}} K_{1}^{\varepsilon_{A}} \\
& \frac{\partial Y_{2}}{\partial G_{2}}=\gamma \frac{Y_{2}}{D_{2}} N_{2}^{\varepsilon_{A}-\varepsilon_{R}} K_{2}^{\varepsilon_{A}}
\end{aligned}
$$

Due to the incomplete consideration of the interregional interdependencies, the (nonconsidered) productivity impact of integration becomes an externality. Completely uncoordinated policies then may be described by

$$
\left(\frac{g_{s}+\beta}{1+\beta g_{s}}\right)^{\gamma-1}=\frac{1}{k^{\varepsilon_{A}} n^{\varepsilon_{A}-\varepsilon_{R}}} l^{-\lambda} k^{-\alpha}
$$

Utilizing equations (3), (6) and solving (17) for $\theta$ provides the explicit representation of $\theta^{a}$ as

$$
\theta^{a}\left(k, \varepsilon_{A}, \beta, \ldots\right)=\frac{\Omega-\beta}{(1-\Omega \beta) \Upsilon}, \quad \text { with } \quad \Omega \equiv\left(k^{\varepsilon_{A}} n^{\varepsilon_{A}-\varepsilon_{R}} k^{\alpha} l^{\lambda}\right)^{\frac{1}{1-\gamma}}
$$

and $\Upsilon$ from (12). Figures $5(\mathrm{a})-5(\mathrm{c})$ plot $\theta^{a}(k)$ for selected parameter constellations of $\varepsilon_{A}$ and $\beta$.

The interdependency between private and public sector is as follows. If both regions are symmetric, $l=n=1$, and spreading of private activity applies (i.e. $k=1$ ), the

\footnotetext{
${ }^{16}$ This setting corresponds to the Cournot-Nash duopoly.

${ }^{17}$ Notice that compared to marginal productivities in the planner setting in equations (9a) and (9b), the integration term is missing.
} 


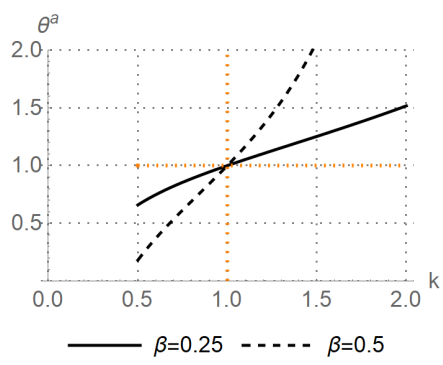

(a) $\varepsilon_{A}=-0.2$ : positive effect dominates

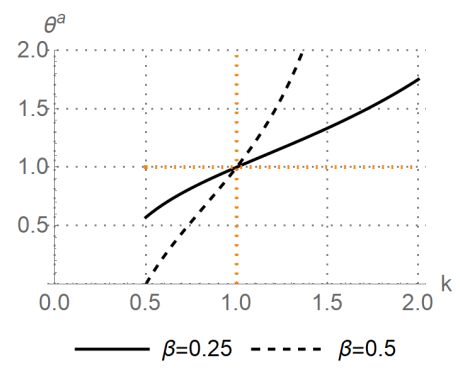

(b) $\varepsilon_{A}=0$ : positive effect dominates

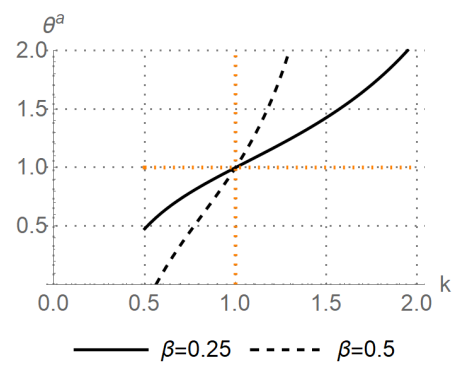

(c) $\varepsilon_{A}=0.2:$ positive effect dominates

Figure 5: $\quad \theta^{a}\left(k, \ldots \varepsilon_{A}, \beta \ldots\right)$ based on equation (18) for selected values of integration and scale; other parameters: $l=1, n=1$ (which implies no impact of $\varepsilon_{R}$ ), $\alpha=0.5$.

right hand side of equation (17) is unity and the uncoordinated solution implies equally distributed government expenditure. This result relies on the assumption of symmetric factor endowment such that both regions symmetrically disregard the productivity impact of their public input on the respective other region. Both governments, although they neglect the option to shift public expenditure back and forth between the two regions and thus choose 'suboptimal' levels of expenditure, deviate with their decision to the same extent from the planner optimum. Consequently, since the externality is also symmetric, it cancels from a relative perspective. In case of spreading, $\theta^{a}(k)=1$ results (which coincides with $\theta^{*}(k)=1$ in the case of coordinated policies, compare equation (13)). This result also holds independent of scale or integration - as can again be seen in the intersection of dashed and solid functions in Figures 5(a) $-5(\mathrm{c})$.

If in contrast private activity is concentrated, i.e. if $k>1$ is realized, public expenditure shares will be adjusted according to

$$
\frac{d \theta^{a}}{d k}=\frac{\left(1+\varepsilon_{A}\right)}{\left(1-\beta^{2}\right)} \frac{\left(1+\beta g_{s}\right)^{\gamma}}{\left(g_{s}+\beta\right)^{\gamma-2}} \frac{l^{-\lambda} k^{-\alpha-2}}{\left(n^{\varepsilon_{A}-\varepsilon_{R}} k^{\varepsilon_{A}}\right)^{2} n}-\left(1+\varepsilon_{A}\right) \frac{\theta^{a}}{k} \quad \gtrless 0
$$

Again the total effect results from the interaction of the aforementioned three partial effects: complementarity, substitution and integration effect. While the substitution effect does not differ from the planner setting, the ambiguous integration effect is less distinct in the uncoordinated setting. Since both governments only consider the productivity impact of public services arising in their own region, the shift of public expenditure building on integration is less pronounced. Integration effect and complementarity effect add up to the first summand in equation (19) which is unequivocally positive. Especially in case of negative values of scale, the integration effect does not longer dominate the total effect (compare Figure 6 for a visualization of the partial effects). Although the sign of $\varepsilon_{A}$ determines which effect (complementarity or substitution) is being reinforced, the integration effect looses its dominance for the total effect.

As can be seen in Figure 5, for reasonable parameter settings, altogether the positive relationships between private and public input dominate. The ambiguity of the total effect discussed for coordinated policies disappears. In the absence of coordination, a rise in $k$ unambiguously increases the productivity of the public input prioritizing the larger region. Hence the government expenditure share in the larger region increases more rapidly than 


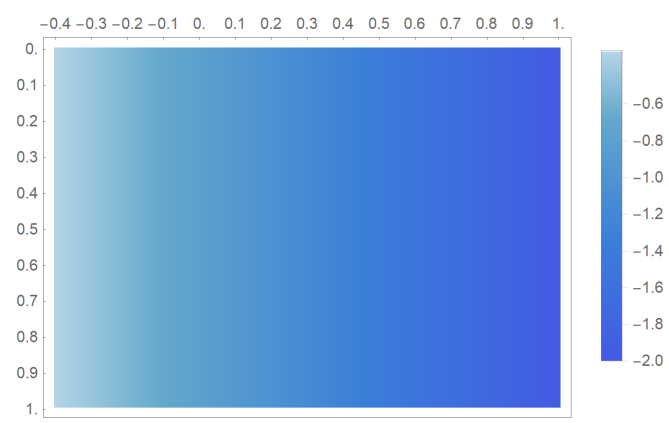

(a) negative substitution effect

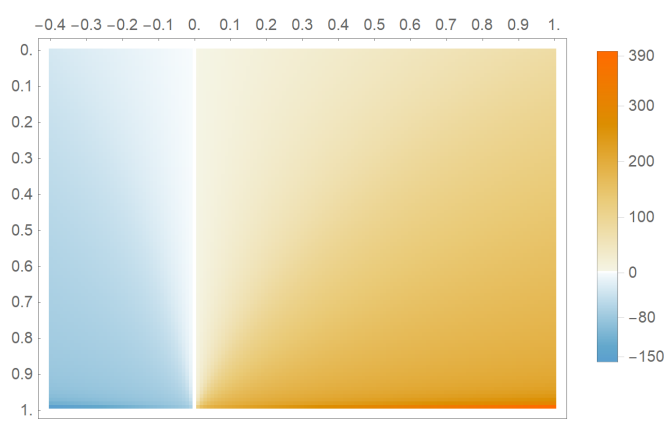

(c) ambiguous integration effect

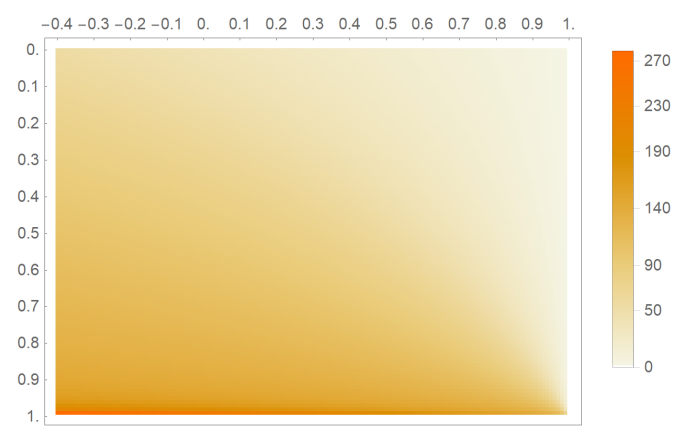

(b) positive complementarity effect

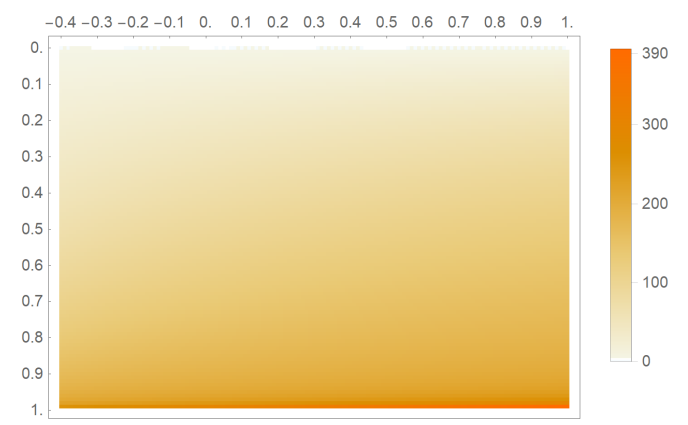

(d) positive total effect

Figure 6: $d \theta^{a}\left(k, \ldots \varepsilon_{A}, \beta \ldots\right) / d k$ from (19) for $k=1$; partial effects and ambiguous total effect in case of autarky depending upon integration (vertical axis) and scale (horizontal axis); total effect is sum of three partial effects; horizontal axis: $\varepsilon_{A} \in(-0.4,1)$; vertical axis: $\beta \in(0,1)$, other parameters: $l=1, n=1$ (which implies no impact of $\varepsilon_{R}$ if $n=1$ ), $\alpha=0.5$; plots are based on equations (42), (48), and (49); colorbars document effect strength (color intensity) and sign (blue: negative; red: positive).

in the smaller region, $\theta^{a}$ increases. The relatively larger region will then also be endowed with relatively more public input. As a consequence, uncoordinated government decisions on the public input unambiguously amount to an agglomeration force.

\subsection{Partial coordination}

Aside from the polar scenarios of full and no coordination it is also quite natural to think about economies in which the large region's government behaves as a 'Stackelberg-leader' who anticipates the behavior of the follower. For instance, if a metropolitan area provides a university, the neighboring small city will discard to supply a university itself which affects the investment incentives of the large region. Or, if one city decides to close some museums, the other city will consider to amplify its cultural environment. We assume such a leader-follower setting in which the leading region 1 and the following region 2 behave differently. More precisely, the smaller region 2 takes the amount of the larger region's public input as given and reacts on it optimally. Exploiting this behavior, the leading region relegates (at least part of the) expenditure to the (remote) follower region.

Formally, the larger region 1 anticipates the behavior of the smaller region 2 and chooses the amount of the public input subject to the constraint that region 2 will adjust its public 
input accordingly. Given these assumptions, the decision rule of the follower region 2 is analog to the uncoordinated policy as derived in Section 4.2 and consists in equalizing marginal cost and marginal benefit, $\partial Y_{2} / \partial G_{2}=1$ from (16b), hence

$$
\gamma \frac{Y_{2}}{D_{2}} N_{2}^{\varepsilon_{A}-\varepsilon_{R}} K_{2}^{\varepsilon_{A}}=1
$$

Marginal productivity of $G_{2}$ is affected by the amount of the public input in region $1, G_{1}$, since this enters the follower region's global public input, $D_{2}$, if integration prevails, i.e. if $\beta>0$. Hence, public expenditure in the follower region 2 is adapted to the observed amount of $G_{1}$ such that condition (20) is fulfilled. The smaller region 2 adjusts its expenditure accordingly and this results in

$$
\frac{d G_{2}}{d G_{1}}=-\frac{\partial\left(\gamma \frac{Y_{2}}{D_{2}} N_{2}^{\varepsilon_{A}-\varepsilon_{R}} K_{2}^{\varepsilon_{A}}\right) / \partial G_{1}}{\partial\left(\gamma \frac{Y_{2}}{D_{2}} N_{2}^{\varepsilon_{A}-\varepsilon_{R}} K_{2}^{\varepsilon_{A}}\right) / \partial G_{2}}=-\beta n^{\varepsilon_{A}-\varepsilon_{R}} k^{\varepsilon_{A}}
$$

Due to integration, an increase in the public input in region 1 induces an increase in the global public input which is available in region $2, D_{2}$. The associated decrease of marginal productivity leads to a reduction in the chosen amount of public input in region $2, G_{2}$. This effect is larger the more pronounced the integration and the larger the scale effects in the public services. However, the leader region 1 anticipates this reaction of follower region 2 within its own optimization. When calculating the marginal benefit of public input, region 1 takes into account that the public input of region 2 will be the lower, the higher the amount of the public input of region 1. Put differently, the government in region 1 calculates both the positive direct and the induced indirect replacement effect and equalizes the associated marginal product to the marginal costs. The optimization rule of the leader region becomes

$$
\frac{d Y_{1}}{d G_{1}}=\frac{\partial Y_{1}}{\partial G_{1}}+\frac{\partial Y_{1}}{\partial G_{2}} \frac{\partial G_{2}}{\partial G_{1}}=\gamma \frac{Y_{1}}{D_{1}} N_{1}^{\varepsilon_{A}-\varepsilon_{R}} K_{1}^{\varepsilon_{A}}\left(1-\beta^{2}\right) \stackrel{!}{=} 1
$$

Combining the two optimality conditions (20) and (22) results in

$$
\left(\frac{g_{s}+\beta}{1+\beta g_{s}}\right)^{\gamma-1}=\frac{1}{\left(1-\beta^{2}\right) k^{\varepsilon_{A}} n^{\varepsilon_{A}-\varepsilon_{R}}} l^{-\lambda} k^{-\alpha}
$$

The right hand side of (23) exceeds the right hand side of equation (17) describing the uncoordinated solution. Hence, the left hand side has to be higher too, which implies a lower value of $\theta^{s}$ compared to the uncoordinated setting. The larger region 1 anticipates the reaction in the public input of region 2 , hence it decreases its local expenditure. As a consequence, other things being equal, the ratio of public inputs, $\theta^{s}<\theta^{a}$ for all levels $k>$ $1{ }^{18}$ Accordingly, partial coordination in the leader-follower-setting serves as a dispersion force compared with the uncoordinated setting due to the restraint in public expenditure of the larger region. This holds for all parameter constellations, except for $\beta=0$ where $\theta^{s}=\theta^{a}=\theta^{*}$.

The explicit representation of $\theta^{S}(k)$ may be derived by utilizing equations (3), (6) and solving (23) for $\theta$ as

$$
\theta^{S}\left(k, \varepsilon_{A}, \beta, \ldots\right) \equiv \frac{\Lambda-\beta}{(1-\Lambda \beta) \Upsilon}, \quad \text { where } \quad \Lambda \equiv\left(\left(1-\beta^{2}\right) k^{\varepsilon_{A}} n^{\varepsilon_{A}-\varepsilon_{R}} k^{\alpha} l^{\lambda}\right)^{\frac{1}{1-\gamma}}
$$

\footnotetext{
${ }^{18}$ Compare also equations (18) and (24).
} 
and again $\Upsilon$ from (12). ${ }^{19}$

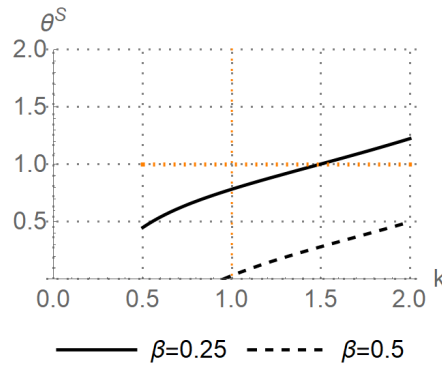

(a) $\varepsilon_{A}=-0.1:$ positive effect dominates

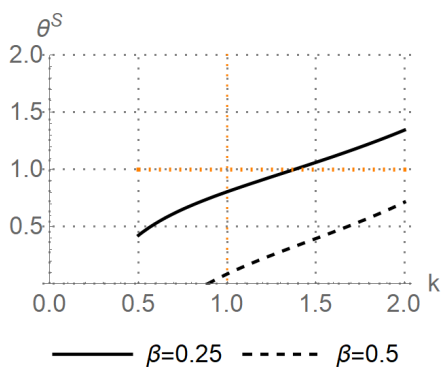

(b) $\varepsilon_{A}=0$ : positive effect dominates

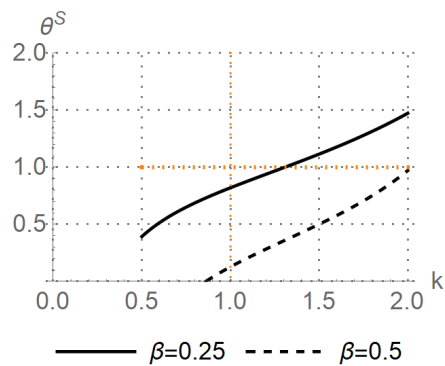

(c) $\varepsilon_{A}=0.1:$ positive effect dominates

Figure 7: $\theta^{S}\left(k, \ldots \varepsilon_{A}, \beta \ldots\right)$ based on equation (24) for selected values of integration and scale; other parameters: $l=1, n=l$ (which implies no impact of $\varepsilon_{R}$ ), $\alpha=0.5$. Notice that for $n=l=k=1$ no symmetry results but $\theta^{S}<k$

Figures 7(a)-7(c) plot $\theta^{s}(k)$ for selected parameter constellations of $\varepsilon_{A}$ and $\beta$. Even in case of full symmetry, i.e. if $n=l=k=1, \theta^{s}$ unequivocally falls below unity. ${ }^{20}$ The leading region anticipates the effort of the smaller region and pursues a beggar-thy-neighbor policy. The arising level of $\theta^{s}$ decreases with integration, $\beta$, and increases with scale, $\varepsilon_{A}$ (compare Figure 7$)$. Put differently, equalized public activity $\left(\theta^{s}=1\right)$ only results if private capital is concentrated in the bigger region 1 (i.e. if $k>1$ ). This effect is reinforced by integration which facilitates the access to the other region's public input.

If the starting point is not the spreading equilibrium but private capital is concentrated $(k>1)$, regional governments' decisions on the amount of public expenditure will be driven by the three above mentioned partial effects:

$$
\frac{d \theta^{s}}{d k}=\frac{\left(1+\varepsilon_{A}\right)}{\left(1-\beta^{2}\right)^{2}} \frac{\left(1+\beta g_{s}\right)^{\gamma}}{\left(g_{s}+\beta\right)^{\gamma-2}} \frac{l^{-\lambda} k^{-\alpha-2}}{\left(n^{\varepsilon_{A}-\varepsilon_{R}} k^{\varepsilon_{A}}\right)^{2} n}-\left(1+\varepsilon_{A}\right) \frac{\theta^{s}}{k} \quad \gtrless 0
$$

As in the uncoordinated setting, the positive complementarity effect and the ambiguous integration effect sum up to the first term which unambiguously is positive: concentration in private capital ceteris paribus increases concentration in public expenditure. Figure 8 shows that for reasonable parameter settings, this positive effect dominates the negative substitution effect.

Private capital concentration implies that there is more need for public services in the larger region. This positive effect on $\theta^{s}$ is larger in the partial coordination setting than with uncoordinated policies, since the larger region takes the reaction of the smaller region into account. Any increase in public expenditure of region 1 immediately decreases government activity in region 2 (see negative sign in (21)). If region 1 is a Stackelberg leader, it will compensate for this reduction and increase public input even more. The total effect results to be positive for all reasonable parameter settings and even stronger

\footnotetext{
${ }^{19}$ Note that reasonable values of $\theta^{s}$ may only be derived for restricted domains of $\varepsilon_{A}$ and $\beta$. Figure 14 in the Appendix gives a graphical representation of valid parameter constellations (the red area - where $\theta^{s}>$ $0)$.

${ }^{20}$ Compare also the matrix plot in Appendix 9.2.
} 


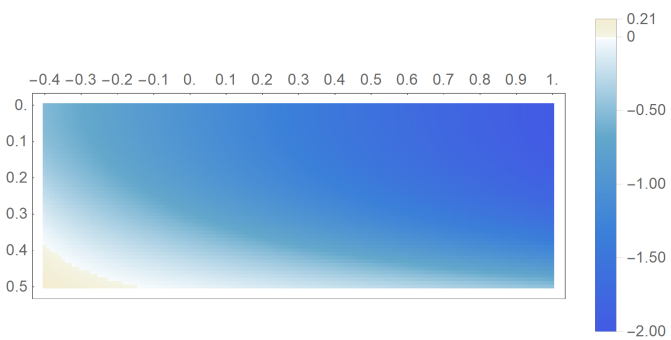

(a) negative substitution effect

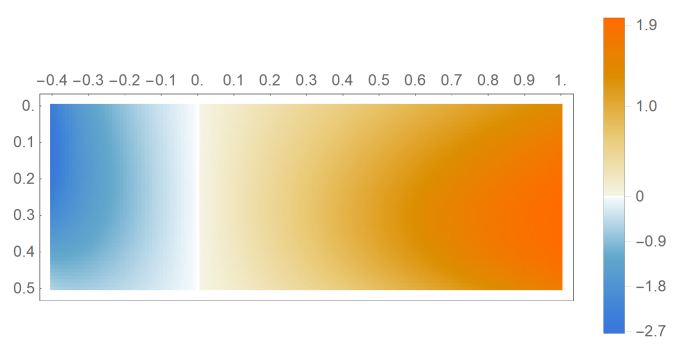

(c) ambiguous integration effect

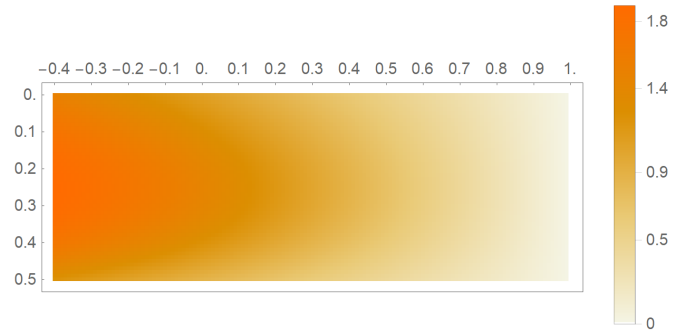

(b) positive complementarity effect

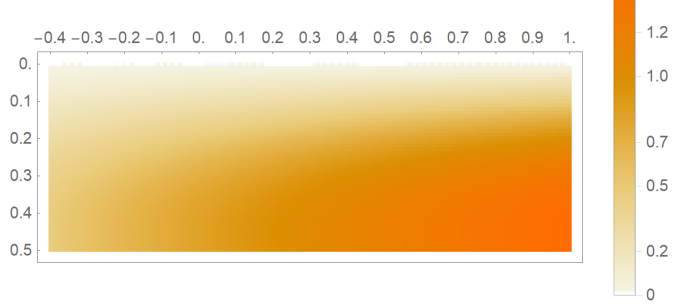

(d) positive total effect

Figure 8: $d \theta^{S}\left(k, \ldots \varepsilon_{A}, \beta \ldots\right) / d k$ with partial effects as derived in equations (42), (52), (53) and $\theta^{S}$ from (24) for $k=1 \Rightarrow \theta^{S}<0$; partial effects and ambiguous total effect in case of autarky depending upon integration (vertical axis) and scale (horizontal axis); total effect is sum of three partial effects; horizontal axis: $\varepsilon_{A} \in(-0.4,1)$; vertical axis restricted parameters: $\beta \in(0,0.5)$, other parameters: $l=1, n=1$ (which implies no impact of $\varepsilon_{R}$ if $n=1$ ), $\alpha=0.5$; plots are based on equation (42), (52) and (53); colorbars document effect strength (color intensity) and sign (blue: negative; red: positive).

than for uncoordinated policies. Hence, the agglomeration force resulting from partial coordination is stronger, too.

As a consequence of $\theta^{s}<1=k$, the negative substitution effect varies for given levels of $\varepsilon_{A}$ with $\beta$. Its absolute value decreases with integration and increases with scale. Other things being equal, it is more pronounced the higher $\varepsilon_{A}$ and the lower $\beta{ }^{21}$

\section{$5 \quad$ Private sector optimization}

We now shift the perspective from optimizing local governments to optimizing private firms that interpret the spatial distribution of public activity as given. ${ }^{22}$ Formally spoken, we focus on $k^{*}(\bar{\theta})$.

Following Bröcker (2005) we argue that investment in physical capital is spatially mobile across the regions such that capital accumulation is realized in the region delivering the

\footnotetext{
${ }^{21}$ An overview of the impact of integration and scale effects on the signs of the partial effects compared for the three coordination schemes can be found in Table 2 in Appendix 9.3.4.

${ }^{22}$ This section strongly borrows from Ott and Soretz (2010). . The expenditure share ratio $\bar{\theta}$ is based on (5) together with the definition of $\theta \equiv \Theta_{1} / \Theta_{2}$, thus affecting private capital productivity and hence individual investment decisions. Notice that the assumption of the exogenous level of $\bar{\theta}$ neglects feedback effects between private and public optimization decisions. We turn to this point in Section 6 .
} 
higher marginal returns. Within a two-region setting, the ratio of marginal productivities of physical capital may be calculated as

$$
R \equiv \frac{\partial Y_{1} / \partial K_{1}}{\partial Y_{2} / \partial K_{2}}
$$

A spatial equilibrium is defined as a stationary capital distribution which requires $R=1$, with non-negative investment in both regions. Then firms are indifferent as to invest either in region 1 or 2, agglomeration and dispersion forces cancel. ${ }^{23}$ Implementing equations (1)(6) into (26) yields

$$
R=l^{\lambda} k^{\alpha-1}\left(\frac{g_{s}+\beta}{1+\beta g_{s}}\right)^{\gamma-1} \cdot\left(\frac{\alpha\left(g_{s}+\beta\right)+\gamma \varepsilon_{R} g_{s}}{\alpha\left(1+\beta g_{s}\right)+\gamma \varepsilon_{R}}\right)
$$

Taking logarithms of (27) leads to the relationship

$$
R \gtrless 1 \Longleftrightarrow i(k, \bar{\theta}, \ldots) \gtrless-\lambda \ln l
$$

with $i(k, \bar{\theta}, \ldots)$ representing the productivity (or return) differential between the regions given by

$$
i(k, \bar{\theta}, \ldots) \equiv(\alpha-1) \ln k+(\gamma-1) \ln \left(\frac{g_{s}+\beta}{1+\beta g_{s}}\right)+\ln \left(\frac{\alpha\left(g_{s}+\beta\right)+\gamma \varepsilon_{R} g_{s}}{\alpha\left(1+\beta g_{s}\right)+\gamma \varepsilon_{R}}\right)
$$

The distribution of governmental activity, $\bar{\theta}$, enters this term via $g_{s}$. Together with the spatial distribution of immobile labor, reflected by the threshold $-\lambda \ln l$ from (28), it determines the direction of investment flows. ${ }^{24}$ If the productivity differential exceeds the threshold, capital is more productive in region 1 such that $k$ increases until the spatial equilibrium condition is met at the intersection of $i(k)$ and the horizontal axis (representing the threshold for $l=1$ ) in Figure 9(a). Analog arguments apply for productivity differentials falling below the threshold.

In line with the argumentation in geographical economics, for symmetric regions, agglomeration forces destabilize a spreading equilibrium while dispersion forces have a stabilizing impact. Other things being equal, either a unique and stable spatial equilibrium or multiple equilibria with different stability characteristics arise. Both scenarios are illustrated in Figure 9(a) for the case of completely symmetric regions (i.e. if $n=l=k=\theta=1$ ).

\footnotetext{
${ }^{23}$ Since the basic framework assumes a growth model, the full description of the spatial equilibrium is characterized by regional capital stocks growing at constant rate. The corresponding growth model is presented in Appendix 9.4.

${ }^{24}$ The threshold $-\lambda l$ is independent of $k$ and $\theta$ and coincides with the horizontal axis if immobile labor is equally distributed across space, i.e. for $l=1$. An increase (a decrease) in the ratio of immobile labor, $l$, shifts the horizontal line downwards (upwards) and thereby affects the equilibrium concentration of private capital. This again is a complementarity effect between production factors: An increase in immobile labour in one region rises capital productivity in this region. Beyond the spreading equilibrium, $R>1$ involves agglomeration forces that foster concentration. In contrast, $R<1$ induces dispersion. Immobile factors ensure the permanent existence of two regions. This might be interpreted in analogy to the no-black-hole condition discussed within models of the New Economic Geography (compare e.g. Brakman, Garretsen, and Marrewijk (2008)).
} 
(i) If $i(k, \bar{\theta}, \ldots)$ is monotone and negatively sloped in $k=1$ (compare the solid line in Figure 9(a)), the spreading equilibrium is unique and stable. For any unequal capital distribution $k \neq 1$ the region which is endowed with more physical capital will experience smaller capital return. Hence, capital investment is directed to the smaller region until spreading is realized. The solid line is exemplary for specific combinations of integration and scale representing stable spreading and the corresponding parameter constellations can be found within the white area in Figure 9(b).

(ii) If instead, $i(k, \bar{\theta}, \ldots)$ is non-monotone, multiple equilibria with different stability characteristics arise (compare the dashed line in Figure 9(a)). Then the agglomeration forces dominate around the spreading equilibrium $k^{*}=1$ making it unstable. Instability implies that deviations from it induce investment in the more productive larger region. Dispersion forces gain importance when the disparity increases and induce a stable coreperiphery equilibrium $k^{* *}>1 .{ }^{25}$ The stable equilibrium is reached when capital productivities are again equalized and $R=1$ applies at $k^{* *}>1$.

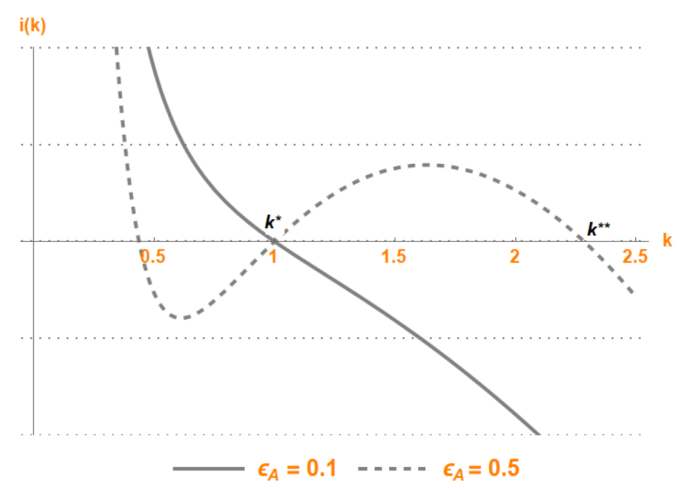

(a) $i(k, \bar{\theta}, \ldots)$ from $(29)$; parameters: $\beta=0.2$, dashed line: $\varepsilon_{A}=0.5$, solid line: $\varepsilon_{A}=0.1$. For $l=1$ the horizontal axis represent the threshold $-\lambda l=0$ from 28 .

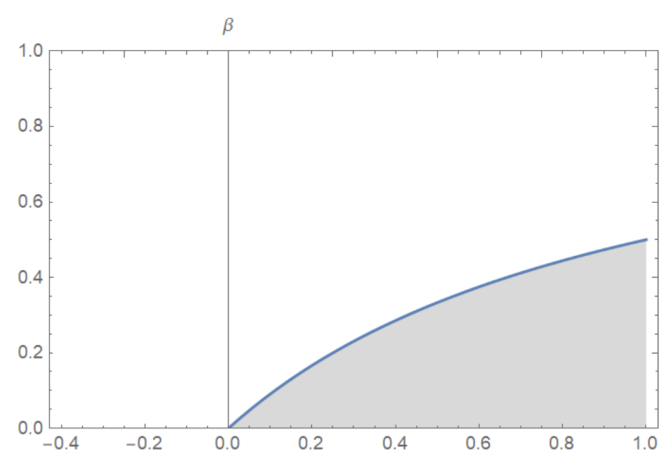

(b) (in)stability of spreading depending upon integration and scale for exogeneous $\bar{\theta}$ : The blue line represents the bifurcation line according to (30); white area: spreading is stable; shaded area: spreading is unstable; $\varepsilon_{A}$ at horizontal axis and $\beta$ at vertical axis

Figure 9: Equilibrium agglomeration and (in)stability of spreading; symmetric factor endowment: $\bar{\theta}=k=n=l=1$, other parameters: $\alpha=0.5, \varepsilon_{R}=1$.

In case of complete symmetry $(\theta=k=n=l=1)$, it is possible to derive a closed form solution for the underlying bifurcation, i.e. to derive those parameter combinations of congestion, scale, and integration that separate stable from unstable equilibria. From a technical perspective, the crucial characteristic is the sign of the slope of $i(k, \bar{\theta}, \ldots)$ from (29) evaluated at the equilibrium capital distribution, $k^{*}=1$. This may be derived by zeroising the first derivative of $i(k, \bar{\theta} \ldots)$ w.r.t $k$, setting $k=1$ and solving for $\beta$ which provides the bifurcation function in (30).

\footnotetext{
${ }^{25}$ The notion of a core-periphery relies on the seminal work of Krugman (1991).
} 


$$
\bar{\beta} \equiv \frac{\varepsilon_{R}\left(\alpha+\varepsilon_{A}\right)-\alpha\left(1+\varepsilon_{A}\right)}{\alpha\left(1+\varepsilon_{A}\right)}
$$

Figure 9 (b) plots $\bar{\beta}\left(\varepsilon_{A}\right)$ for $\alpha=0.5$ and $\varepsilon_{R}=1$. For $\beta>\bar{\beta}$, the spreading equilibrium is stable (white area in Figure 9(b)) whereas for $\beta<\bar{\beta}$, spreading is unstable. Put differently, for $\varepsilon_{A}$ larger than determined in (30), the core-periphery equilibrium will result (shaded area) and for smaller $\varepsilon_{A}$, the spreading equilibrium will be stable.

Again, scale effects $\left(\varepsilon_{A}>0\right)$ can be recognized as agglomeration force: capital return increases in the capital stock and capital is more productive in the larger region. This effect can be seen in Figure 9(b). The shaded area representing core-periphery equilibria is completely located in the area where $\varepsilon_{A}>0$.

Integration $(\beta>0)$ in contrast is a dispersion force: due to integration the smaller region can benefit from any productivity advantage taking place in the larger region. Other things being equal, in Figure 9(b) more pronounced integration implies moving upwards and eventually leads into the white area representing spreading equilibria.

In Section 6 we show that for a huge variety of parameters, public coordination activities strengthen agglomeration forces thereby imposing a destabilizing impact on the spreading equilibrium.

\section{$6 \quad$ Feedback effects as drivers of regional inequality}

So far, feedback effects between decisions of the private and the public sector have been neglected. Section 4 analyzes optimization considerations of public actors for a given distribution of private capital while Section 5 considers private investment decisions for a given distribution of public activity. Feedback effects, however, arise since private and public sector are interdependent and this may activate processes of cumulative causation (as visualized in Figure 10). As will be shown below, feedback effects mostly destabilize the spreading equilibrium. Note that this result is in line with what we observe worldwide concerning ongoing urbanization which seems to apply independent of the institutional setting.

In this section we derive how the stability characteristics of the spreading equilibrium will be affected if feedback effects apply. Again, we assume full symmetry and especially focus on the impact of the bifurcation parameters integration and scale. ${ }^{26}$ Starting point is the spreading equilibrium, $k=1$.

As in Section 5, we focus on the concept of the spatial equilibrium based on equations (26)-(28) but we now replace the so far exogenous ratio $\bar{\theta}$ by those levels that have been explicitly determined by the two governments within the different coordination schemes in Section 4 , i.e. by $\theta^{*}(k)$ from equation (11), $\theta^{a}(k)$ from (18) and $\theta^{s}$ from (24). ${ }^{27}$

\footnotetext{
${ }^{26}$ Considering bifurcation as derived in (30) highlights that also relative congestion acts as bifurcation parameter. The simulations as well as Figures $9(\mathrm{~b})$ and 12 assume $\varepsilon_{R}=1$.

${ }^{27}$ As a consequence, the return differential $i(k, \theta(k) \ldots)$ from $(29)$ can be reformulated to only depend upon $k$.
} 


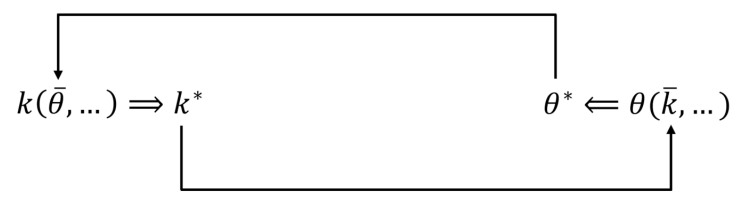

Figure 10: mutual interdependencies, feedback effects, and cumulative causation

As a reference, Figures 11(a)-11(d) plot the return differentials without feedback effects to be compared to those setting in which feedback effects are taken into account, compare Figures 11(e)-11(p). Recall that the slope of the return differential function, $i(k)$, in the spreading equilibrium reflects the associated stability characteristics.

In the reference scenario, spreading is stable with the single exception of high scale effects and low integration (compare dashed line in Figure 11(a)). If instead one allows for full coordination (compare Figures 11(e) - 11(h)), the stability characteristics of spreading change dramatically. Now spreading is only in one single case stable, namely if there is congestion (negative scale) and integration is high (compare the dashed line in Figure 11(g) and more broadly the filled area in Figure 12). Key driver of this result is the integration effect as derived in Section 4.1. Only for high integration and low scale, and only in case of full coordination, the dampening integration effect is strong enough to keep the spreading equilibrium stable. In case of no coordination (compare Figures 11(i)-11(1)), the integration effect is weaker and altogether spreading unequivocally gets unstable. In case of partial coordination (Figures $11(\mathrm{~m})-11(\mathrm{p})$ ), an unequivocally unstable core-periphery equilibrium exists with the leading region representing the core. The size of the core is larger for high levels of integration and decreases with the level (though not the absolute value) of scale.

For the planner setting, Figure 12 highlights how the range of the bifurcation parameter constellations of $\beta$ and $\varepsilon_{A}$ leading to an unstable spreading equilibrium is extended if feedback effects are taken into account. Similar to Figure 9(b), the shaded areas represent combinations of integration and scale leading to unstable spreading equilibria. The basic pattern that can be seen in case of exogenous $\theta$ persists and even gets reinforced, while the basic mechanism remains: increasing scale and/or decreasing integration destabilize the spreading equilibrium. In any case, coordination effects strengthen agglomeration forces.

A closer look at the two benchmark cases of no coordination and full coordination helps to understand the reason for the prevailing instability. One key result is the emergence of the positive externality that the provision of a public input by one region represents for the respective other region in case of no coordination. ${ }^{28}$ Related to this is the fact that the negative substitution effect then unequivocally is dominated. Besides, we argued that the direction of the integration effect depends upon the sign of scale, $\varepsilon_{A}$. It basically allows for a positive relationship between the private and the public sector (thus reinforcing the complementarity effect) if $\varepsilon_{A}$ is positive whereas the integration effect reinforces the negative substitution effect, if $\varepsilon_{A}$ is negative.

It is possible to derive the described effects more broadly and thus to discuss whether

\footnotetext{
${ }^{28}$ Note that an externality also arises in case of partial coordination. However, the subsequent discussion only compares no coordination and full coordination.
} 


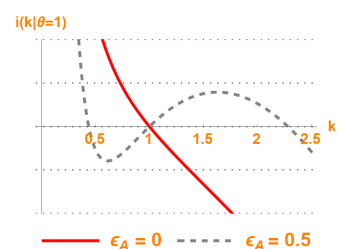

(a) $\bar{\theta}=1, \beta=0.2$

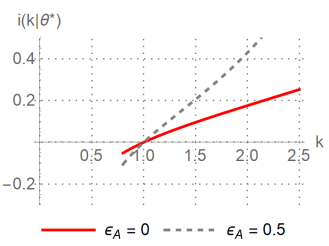

(e) $\theta=\theta^{*}, \beta=0.2$

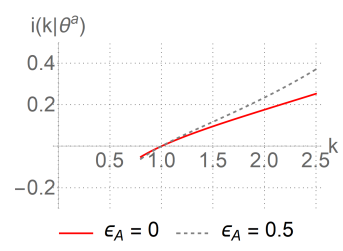

(i) $\theta=\theta^{a}, \beta=0.2$

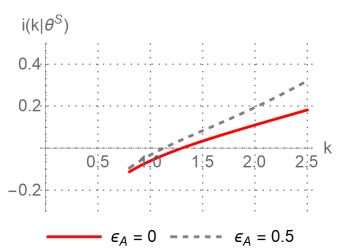

(m) $\theta=\theta^{S}, \beta=0.2$

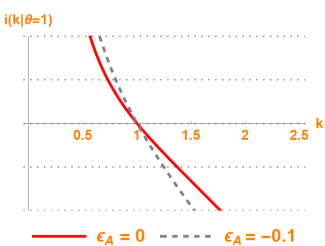

(b) $\bar{\theta}=1, \beta=0.2$

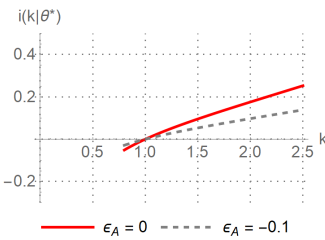

(f) $\theta=\theta^{*}, \beta=0.2$

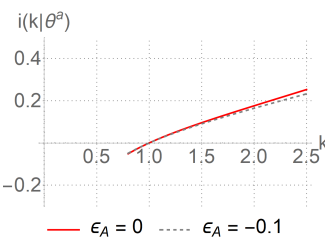

(j) $\theta=\theta^{a}, \beta=0.2$

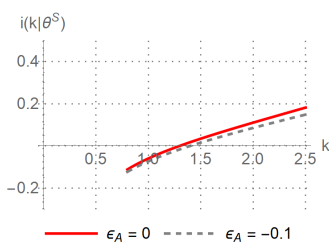

(n) $\theta=\theta^{S}, \beta=0.2$

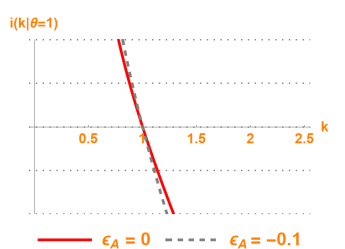

(c) $\bar{\theta}=1, \beta=0.35$

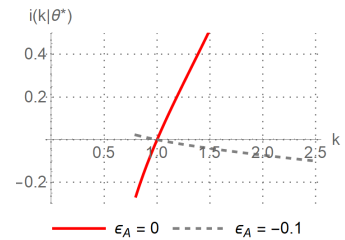

(g) $\theta=\theta^{*}, \beta=0.6$

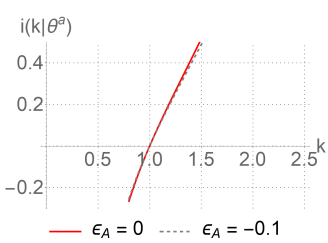

(k) $\theta=\theta^{a}, \beta=0.6$

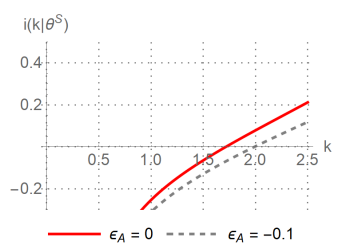

(o) $\theta=\theta^{S}, \beta=0.35$

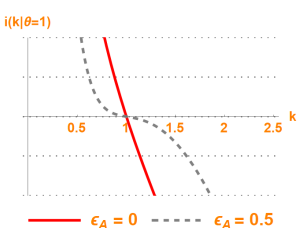

(d) $\bar{\theta}=1, \beta=0.35$

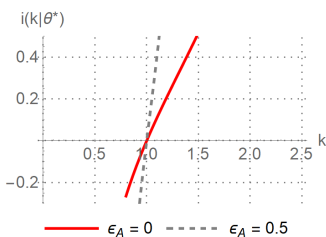

(h) $\theta=\theta^{*}, \beta=0.6$

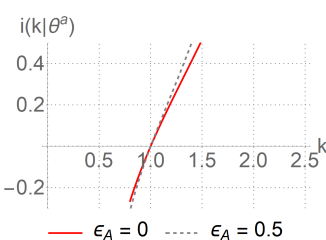

(l) $\theta=\theta^{a}, \beta=0.6$

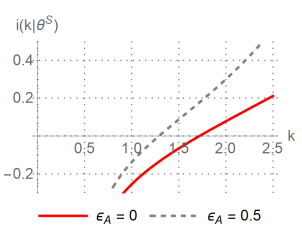

(p) $\theta=\theta^{S}, \beta=0.35$

Figure 11: productivity differential for selected values of $\beta(=0.2,0.35,0.6)$ and $\varepsilon_{A}(=-0.1,0,0.5)$ and for various coordination schemes $\left(\bar{\theta}=1, \theta^{*}, \theta^{a}, \theta^{S}\right)$.

Figures 11(a)-11(d) neglect feedback effects (i.e. consider $\theta=1$ as exogenous and constant, $i(k \mid \bar{\theta}=1)$ )

Figures 11(e)-11(h): full coordination, $\left(i\left(k \mid \theta^{*}\right)\right)$;

Figures 11(i)-11(l): no coordination, $\left(i\left(k \mid \theta^{C}\right)\right)$;

Figures $11(\mathrm{~m})-11(\mathrm{p})$ : partial coordination, $\left(i\left(k \mid \theta^{S}\right)\right)$

connecting perspective for all scenarios is given by $\varepsilon_{A}=0$ (red line - which is included in all subfigures) 


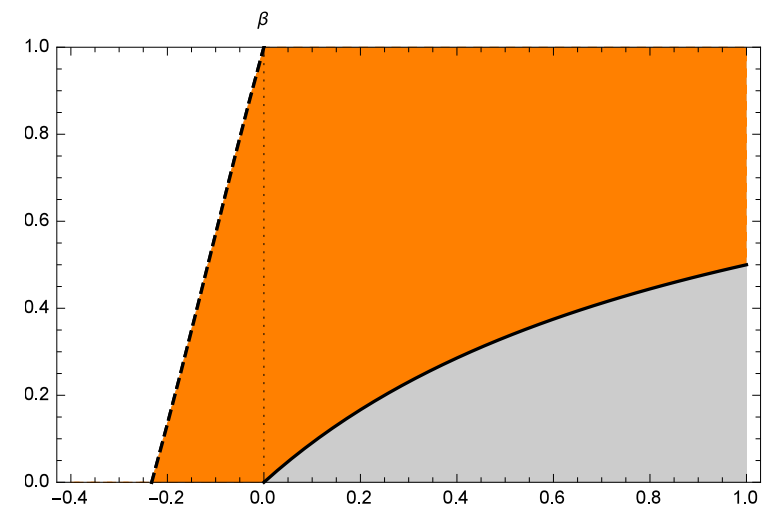

Figure 12: (in)stability of spreading depending upon integration and scale for endogenous $\theta^{*}$; white area: spreading is stable; shaded area: spreading is unstable; shift of bifurcation line from solid to dashed, if feedback effects are taken into account (recall: solid line is identical to Figure 9(b)); grey shaded area: instability area planner without feedback effects, gets extended if feedback effects are taken into account - red shaded area on top; $\varepsilon_{A}$ at horizontal axis and $\beta$ at vertical axis separating stable and unstable spreading equilibria; other parameters: $n=l=k=1, \alpha=0.5$.

concentration of government expenditure in the uncoordinated setting ends up to be higher or lower than for coordinated policy. To do so, formally one might start by comparing the right hand side of equations (10) and (17)

$$
\frac{1-\beta k^{\varepsilon_{A}} n^{\varepsilon_{A}-\varepsilon_{R}}}{k^{\varepsilon_{A}} n^{\varepsilon_{A}-\varepsilon_{R}}-\beta} l^{-\lambda} k^{-\alpha} \lessgtr \frac{1}{k^{\varepsilon_{A}} n^{\varepsilon_{A}-\varepsilon_{R}}} l^{-\lambda} k^{-\alpha} \quad \Leftrightarrow \quad k^{\varepsilon_{A}} n^{\varepsilon_{A}-\varepsilon_{R}} \gtrless 1
$$

The result mainly depends on the characteristics of the public input as captured by $\varepsilon_{A}$. If scale effects are positive $\left(\varepsilon_{A}>0\right)$, agglomeration $(k>1)$ implies $k^{\varepsilon_{A}}>1$. For $n$ near or equal to $1, n^{\varepsilon_{A}-\varepsilon_{R}} k^{\varepsilon_{A}}>1$ follows immediately, and the upper inequality signs in equation (31) apply. Hence the right hand side in equation (17) is larger than in (10). Contrariwise, if scale effects are negative $\left(\varepsilon_{A}<0\right)$, agglomeration implies $n^{\varepsilon_{A}-\varepsilon_{R}} k^{\varepsilon_{A}}<1$ and therefore the right hand side in equation (17) is smaller than in (10). The left hand side in the respective equations decreases in $\theta$ because

$$
\frac{d\left(\frac{g_{s}+\beta}{1+\beta g_{s}}\right)^{\gamma-1}}{d \theta}=\frac{\partial\left(\frac{g_{s}+\beta}{1+\beta g_{s}}\right)^{\gamma-1}}{\partial g_{s}} \frac{\partial g_{s}}{\partial \theta}=(\gamma-1)\left(\frac{g_{s}+\beta}{1+\beta g_{s}}\right)^{\gamma-2} \frac{1-\beta^{2}}{\left(1+\beta g_{s}\right)^{2}} \frac{g_{s}}{\theta}<0
$$

This implies that the ratio of governmental activity is lower (higher) in the uncoordinated setting than with coordinated policy if scale effects apply:

$$
\varepsilon_{A} \gtrless 0 \quad \Leftrightarrow \quad \theta^{a} \lessgtr \theta^{*}
$$

The reason is the positive externality of the public input on the other region's income which becomes prevalent in the ambiguous integration effect. Both regions neglect this positive effect, hence they underestimate marginal productivity of their public expenditure. As a consequence, they realize a suboptimally low level of the public input. If there are negative scale effects $\left(\varepsilon_{A}<0\right)$, productivity in the smaller region exceeds productivity in the larger region. Hence the resulting distortion is more pronounced in the bigger region (which 


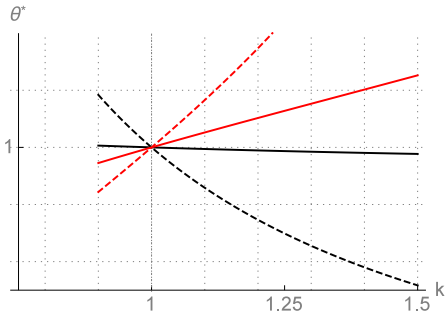

(a) $\varepsilon_{A}=-0.2 \theta^{a}>\theta^{*}$ : negative impact of integration effect (red lines above the black lines)

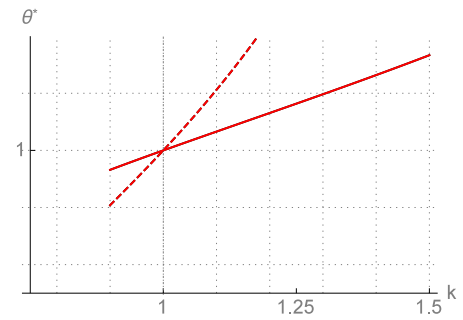

(b) $\varepsilon_{A}=0 \quad \theta^{a}=\theta^{*}$ : no action of integration effect (red and black lines coincide)

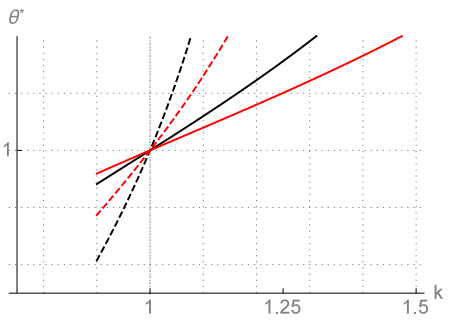

(c) $\varepsilon_{A}=0.2 \quad \theta^{a}<\theta^{*}$ : positive impact of integration effect (black lines above red lines)

Figure 13: Comparing fully coordinated policies (black functions) and uncoordinated policies (red functions); symmetric factor endowment $n=l=1$; solid line: $\beta=0.25$, dashed line: $\beta=0.5$.

neglects a larger productivity impact in the smaller region). This leads to a suboptimally low realization of $\theta^{a}$. If instead there are positive scale effects $\left(\varepsilon_{A}>0\right)$, productivity is lower in the smaller region and so is the distortion. Hence the resulting concentration of government expenditure is suboptimally high. Figure 13 summarizes this and especially demonstrates the ambiguous impact of the integration effect and how this is reinforced by integration.

To conclude, whenever scale effects apply and there is integration $\left(\varepsilon_{A}>0, \beta>0\right)$, the optimal distribution of public input is characterized by concentration in the larger region: $k>1$ leads to $\theta^{*}>1$. Increasing integration reinforces this effect because it promotes the interregional productive use of the public input. With this reason, integration becomes an agglomeration force with respect to the distribution of public input. If additionally coordination is missing and regional governments decide autarkic, integration strengthens agglomeration even if scale effects are absent. In the uncoordinated regime regions choose a suboptimally high concentration of public input (see Figure 13(a)) and integration again reinforces this effect.

\section{$7 \quad$ Results and policy implications}

In economies without feedback effects, i.e. $\bar{\theta}$ exogenously given and constant, compare Section 5 , the following applies: in case of full symmetry a stable spreading equilibrium results for most combinations of integration and scale. Then, integration unequivocally acts as a dispersion force with respect to the distribution of private capital: Even if scale effects are high and set ground for agglomeration forces, a stable spreading equilibrium may be achieved just by sufficiently increasing the degree of integration (compare Figure 9(b)). For low integration, a stable core-periphery structure results (compare $k^{* *}$ in Figure 9(a)) in which both regions grow at identical rates. ${ }^{29}$

In case of endogenous $\theta$, the impact of integration on the stability of spreading is not predetermined, compare Section 4. Instead it mainly depends on the characteristics of

\footnotetext{
${ }^{29}$ This scenario, however, implies divergence in terms of absolute income per capita.
} 
the public input. Scale effects $\left(\varepsilon_{A}>0\right)$ give rise to concentration of the public input and integration reinforces this effect as it allows for the interregional productive use of the public input. Integration acts as catalyst that reinforces either prevailing agglomeration forces (thus destabilizing the spreading equilibrium) or dispersion forces (thus stabilizing the spreading equilibrium). In any case, if dispersion forces are weak, the associated reinforcement is also weak such that the spreading equilibrium remains unstable even if the degree of integration is significantly increased.

If in addition feedback effects are taken into account, compare Section 6, the mechanisms driving the spatial equilibrium are more complex and especially the stability characteristics come to the fore. Notice that due to the complexity of the model, it is then only possible to make statements in or close to the spreading equilibrium. Another influencing factor aside from scale and integration is the underlying institutional setting (i.e. the coordination scheme). In this sense, comparing the settings without and with feedback effects, integration is Janus-faced.

Feedback effects dramatically reduce those parameter combinations of scale and integration that allow a stable spreading equilibrium to result from market forces (compare the respective white areas in Figures 9(b) and 12). The intuition is as follows. The interaction between private and public optimizing agents is crucial for the spatial distribution of economic activity. Access intensity to the remote public input is driven by integration. Private individuals invest in the region delivering the higher profitability of private capital thereby assuming a certain endowment with public capital. Public agents, on their end, assume a given distribution of private capital stocks and then decide upon the provision of the public input based on efficiency considerations of the public investment. If the two governments do not jointly decide, the positive productivity impact of the public input in the respective remote region becomes an externality. Although perceived as being independent from the perspective of the actors, private and public decisions are mutually interdependent thus setting ground for feedback effects. Taking feedback effects between the private and the public sector into account induces a process of cumulative causation with mutual reinforcements between the private and the public investment decisions. This is key to the resulting spatial distribution of economic activity. It also dramatically changes the stability characteristics of the spreading equilibrium in the following sense. Deviating from the spreading equilibrium, any initial return differential will persist and perpetually drive a wedge between the local capital productivities. As as consequence, private investment flows to the larger region thereby triggering concentration of public expenditure which again reinforces concentration of private capital. As a result of the feedback loops, agglomeration forces dominate for most combinations of integration and scale thus destabilizing the spreading equilibrium. As soon as there is one region with a (slightly) larger capital stock, this region's government will decide to provide more public input such that the productivity of private capital increases and the larger region attracts even more capital. In case of feedback effects, integration forces are for almost any prevailing degree of scale not strong enough to compensate the strong agglomeration forces. Finally, state (power) asymmetries make it impossible to achieve spreading as a result of market dynamics.

This result is in strong line with the worldwide empirical evidence of ongoing spatial concentration of economic activity - independent of any institutional setting. Any existing divergence continuously increases. At the same time it challenges the convergence goal of 
the EU.

The associated policy implications cover a variety of facets. The model makes it vividly clear that even if the two regions are completely symmetric, the resulting spatial equilibrium is not necessarily stable. A policy aimed exclusively at convergence as such is therefore not enough. On the contrary, any convergence policy must have the associated stability impact in mind. The stability characteristics are determined by a variety of influencing factors and their interaction, so such an accompanying policy is anything but trivial.

Where feedback effects take place between the private and public sectors, a precise understanding of the (potentially ambiguous) effects of integration is required. A stabilizing effect of the integration effect results in the case of expenditures for public goods, whose productivity impact is very strongly materialized regionally, as for example in the case of expenditures for public order and safety or housing and community amenities (formally: $\left.\varepsilon_{A}<0\right)$. The locality of the associated public good is thus essential. On the other hand, government spending that is associated with high economies of scale $\left(\varepsilon_{A}>0\right)$ induces agglomeration forces and destabilizes the spreading equilibrium. Regardless of the public input, an increase in the degree of integration has the effect of strengthening the respective effects. But since agglomeration forces almost always dominate, integration strengthens this effect and will not become a game changer regarding the equilibrium's stability characteristics. Governments should be clear about the underlying transmission channels.

Any policy aiming at convergence should take accompanying measures to stabilize convergence. This is not automatically the result of market incentives. Alternatively, one solution could be for states not to change their level of expenditure permanently, but to keep it constant. In this case, declining marginal returns on accumulated private capital would lead to a standstill of investment incentives as the capital stock rises, so that at least a stable core-periphery structure can be achieved as a spatial equilibrium. Especially in these times of increasing destabilization, it may even be explicitly opportune for the international community to agree on the type and level of public input and not to regularly revise these decisions. The important role would then be to be a reliable partner for the optimizing private actors. Raising awareness for the complex interdependencies is thus a of major importance for any local agent that decides upon the size of public input and the function for which it is spent.

As already explained, the form of coordination determines the extent to which optimizing state actors internalize the interregional external effects from the provision of public input in the other region. Full internalization only takes place in a full coordination setting. The full coordination setting is also superior for welfare reasons. The reference for a commonly agreed upon policy is the joint income $\left(Y=Y_{1}+Y_{2}\right)$, which is maximized thereby taking into account $G=G_{1}+G_{2}$. Neither Cournot nor Stackelberg setting take this perspective into account. In the case of autarky, the decision-makers focus only on regional income. In a leader-follower-setting it is of particular interest to what extent companies in the leading region can benefit from the productive government spending of the other region.

In any case, policy-makers must be aware that the simple proclamation and its pursuit of the convergence objective falls short of the mark. The model has shown that convergence can almost never be realized as a result of jointly optimizing public and private agents. 
Another important insight from the model, however, is that if the spreading equilibrium is reached, its stability properties and the determinants of stability must be taken more into account. The type of public input plays a central role here, as does the strength of integration.

Finally, when choosing their governance structure, states should consider not only the actual convergence objective but should especially also pay attention to the stability characteristics of an associated equilibrium. However, if stability is a separate (additional) political objective, policy makers must prioritize between the various objectives.

\section{Conclusions}

This paper combines major lines of public economics, growth theory, and New Economic Geography. Our key contribution to the literature is the microfoundation of local governmental policies and how these impact not only on the existence but the stability of the spatial equilibrium which itself is the outcome of private investment decisions for given institutional framework conditions.

In a nutshell: Governmental policies in such a framework cover various dimensions. The degree of integration affects to which extent local public inputs become part of a global public input thus having implications for productivity also in neighboring countries. The type of the public input affects to which extent scale effects apply and if the public input is (partially) congested. Finally, the way how coordination between the two regions is organized, how feedback-loops between public and private agents work and subsequently the relative size of the local public inputs also is crucial.

Policy issues cover the provision (type and size) of a productive public input, integration, and various regional policy coordination schemes. The latter predominantly address efficiency considerations of macroeconomic policies from the perspective of local governments. Key arguments are the recognition of cross-border transmission effects in the light of integrated economies as well as the interplay between private and public sector. Key goal of the paper is to better understand whether economic convergence results by following market incentives and under what conditions such a spatial equilibrium is stable. Special attention is paid to the behavior of local governments. Motivated by several stylized facts on government expenditure, income per capita and the observed worldwide increase of urbanization rates we develop a theoretical model to disentangle the underlying complex economic and political interdependencies. We differentiate the three settings of full coordination (comparable to a social planner's perspective), full autonomy (i.e. governments that decide completely independent from each other on the size of the respective local public input) and the case of partial coordination (in which we assume the governments of the two countries to behave as a leader and a follower in a Stackelberg duopoly). In doing so, we provide a micro-foundation for governmental behavior in a spatial growth model with a productive public input and discuss the implications for the spatial distribution of private economic activity. We also address the stability characteristics for the different coordination schemes and show that governmental coordination may destabilize the spatial equilibrium. Endogenous determination of the public input thus strengthens agglomeration forces and thereby sets ground for a process of cumulative causation which ends up in ongoing spatial concentration. The model is thus well suited to explain the stylized facts 
of ongoing agglomeration processes, irrespective of the underlying institutional framework. This result undermines equalization of living standards - at least as natural outcome of market incentives. In addition, given the recent political instability we especially propose that the governments should not only focus on the convergence goal as such but should especially pay more attention on factors and market incentives that stabilize the spatial equilibrium. Seen through this lens integration may become a game changer if the states refrain from permanently adapting their public investment behavior.

\section{References}

Adam, Christopher S. and David L. Bevan (2005). "Fiscal deficits and growth in developing countries". In: Journal of Public Economics 89(4), pp. 571-597.

Andersen, Torben M., Guiseppe Bertola, John Driffill, Clemens Fuest, Harold James, JanEgbert Sturm, and Branko Urosevic (2018). "It's OK to Be Different: Policy Coordination and Economic Convergence". In: EEAG Report on the European Economy, pp. 6482.

Barro, Robert and Xavier Sala-I-Martin (1992). "Convergence". In: Journal of Political Economy 100(21), pp. 223-251.

Barro, Robert J. (1990). "Government Spending in a Simple Model of Endogenous Growth". In: Journal of Political Economy 98, pp. 103-125.

Barro, Robert J. and Xavier Sala-I-Martin (2004). Economic Growth. 2nd ed. MIT-Press: Cambridge, MA.

Benes, Jaromir, Michael Kumhof, Douglas Laxton, Dirk Muir, and Susanna Mursula (Dec. 2013). The Benefits of International Policy Coordination Revisited. IMF Working Paper WP/13/262. International Monetary Fund. URL: \url\{https : //www . imf . org/ external/pubs/ft/wp/2013/wp13262.pdf\}.

Bleaney, Michael, Norman Gemmell, and Richard Kneller (2001). "Testing the endogenous growth model: public expenditure, taxation, and growth over the long run". In: Canadian Journal of Economics 34(1), pp. 36-57.

Bradford, David F., Richard A. Malt, and Wallace E. Oates (1996). "The Rising Cost of Local Public Services: Some Evidence and Reflections". In: National Tax Journal 22(2), pp. 185-202.

Brakman, Steven, Harry Garretsen, Richard Gigengack, Charles van Marrewijk, and Rien Wagenvoort (1996). "Negative Feedbacks in the Economy and Industrial Location". In: Journal of Regional Science 36(4), pp. 631-651.

Brakman, Steven, Harry Garretsen, and Charles van Marrewijk (Sept. 2002). Locational Competition and Agglomeration: The Role of Government Spending. Working Paper 775. CES ifo.

Brakman, Steven, Harry Garretsen, and Charles van Marrewijk (2008). "Agglomeration and Government Spending". In: Foreign Direct Investment and the Multinational Enterprise. Ed. by Steven Brakman and Harry Garretsen. MIT Press.

Brakman, Steven, Harry Garretsen, and Charles van Marrewijk (2009). The New Introduction to Geographical Economics. Cambridge University Press: Cambridge UK.

Bröcker, Johannes (2005). "Agglomeration and Knowledge Diffusion". In: Urban Dynamics and Growth: Advances in Urban Economics. Ed. by Roberta Capello and Peter Nijkamp. Elsevier: Amsterdam, pp. 609-633. 
Chatterjee, Santanu (2005). "Capital Utilization, Economic Growth and Convergence". In: Journal of Economic Dynamics and Control 29, pp. 2093-2124.

Christie, Tamoya (2012). "The Effect of Government Spending on Economic Growth: Testing the Non-linear Hypothesis". In: Bulletin of Economic Research 66(2), pp. 183-204.

Deeken, Tim and Ingrid Ott (2014). "Integration as a Spatial Institution: Implications for Agglomeration and Growth". In: Man, Space, Environment and Time - Economic Interactions in Four Dimensions. Ed. by Rolf Funck and Werner Rothengatter. Nomos, pp. $413-449$.

Dolls, Mathias, Clemens Fuest, Carla Krolage, Florian Neumeier, and Daniel Stöhlker (2018). Convergence in the EMU: What and How? Research rep. PE 614.502 - May 2018. Directorate-General for Internal Politics of the Union - Economic Governance Support Unit.

Edwards, John H. Y. (1990). "Congestion Function Specification and the 'Publicness' of Local Public Goods". In: Journal of Urban Economics 27, pp. 80-96.

Eicher, Theo and Stephen Turnovsky (2000). "Scale, Congestion and Growth". In: Economica 67 , pp. 325-346.

European Commission (2017). Reflection Paper on the Deepening of the Economic and Monetary Union. Tech. rep. European Commission.

European Commission (Jan. 2020). EU Funding Programmes 2014-2020. accessed January 13, 2020. URL: https://ec.europa.eu/info/strategy/eu-budget/spending/topic/ eu-funding-programmes-2014-2020_en.

Farhad, Mohammad and Michael Jetter (2019). On the Relationship between Trade Openness and Government Size. Working Paper 7832. Category 3: Social Protection. CESifo.

Fischer, Manfred and Peter Nijkamp, eds. (2014). Handbook of Regional Science. Springer. URL: \url\{http://www. springerreference.com/docs/navigation.do?m=Handbook+ of +Regional+Science+ $\ \% 28$ Business+and+Economics $\backslash \% 29$-book270\}.

Franks, Jeffrey, Bergljot Barkbu, Rodolphe Blavy, William Oman, and Hanni Schoelermann (2018). Economic Convergence in the Euro Area: Coming Together or Drifting Apart? Working Paper 18. International Monetary Fund.

Fujita, Masuhisa, Paul Krugman, and Anthony Venables (2001). The Spatial Economy Cities, Regions, and International Trade. MIT Press.

Gemmell, Norman, Richard Kneller, and Ismael Sanz (2016). "Does the composition of government expenditure matter for long-run GDP levels?" In: Oxford Bulletin of Economics and Statistics.

Grüner, Hans-Peter (2013). The Political Economy of Structural Reform and Fiscal Consolidation Revisited. European Economy Economic Papers 487. European Commission.

Hamada, Koichi (1979). "Macroeconomic Strategy and Coordination under Alternative Exchange Rates". In: International Economic Policy. Ed. by R. Dornbusch and J. A. Erenkel. John Hopkins Press, pp. 292-324.

Hamada, Koichi and Masahiro Kawai (1997). "International Economic Policy Coordination: Theory and Policy Implications". In: Macroeconomic Policy in Open Economies. Ed. by Michele U. Fratianni, Dominick Salvatore, and Jürgen von Hagen. Greenwod Press. Chap. 4, pp. 87-144.

Henderson, J. Vernon (1974). "The Sizes and Types of Cities". In: American Economic Review 64, pp. 640-654. 
Hirte, Georg, Christian Lessmann, and André Seidel (2020). "International trade, geographic heterogeneity and interregional inequality". In: European Economic Review 127, p. 103427. DOI: $10.1016 / \mathrm{j}$. euroecorev.2020.103427.

Islam, Nazrul (2003). "What have we learnt from the convergence debate?" In: Journal of Economic Surveys 17(3), pp. 309-362.

Kaldor, Nicholas (1961). "Capital Accumulation and Economic Growth". In: The Theory of Capital. Ed. by F. A. Lutz and D. C. Hague. St. Martin's Press: New York, pp. 177222.

Krugman, Paul (1991). "Increasing Returns and Economic Geography". In: Journal of Political Economy 99, pp. 483-499.

Krugman, Paul (1995). Development, Geography, and Economic Theory. MIT Press: Cambridge, MA.

Lindert, Peter H. (1994). "The Rise of Social Spending, 1880-1930". In: Explorations in Economic History 31(1), pp. 1-37.

Martin, Philippe and Carol Ann Rogers (1995). "Industrial Location of Public Infrastructure". In: Journal of International Economics 39, pp. 335-351.

McKibbin, Warwick J. (1997). "Empirical Evidence on International Economic Policy Coordination". In: Handbook of Macroeconomic Policy in Open Economies. Ed. by Michele U. Fratianni, Dominick Salvatore, and Jürgen von Hagen. Greenwood Press. Chap. 4.

Miller, Marcus and Mark Salmon (1985). "Policy Coordination and Dynamic Games". In: International Economic Policy Coordination. Ed. by Willem H. Buiter and Richard C. Marston. NBER. Chap. 5, pp. 184-227.

Mortensen, Jorgen (2013). Economic Policy Coordination in the Economic and Monetary Union. Research rep. 381. Center for Economic Policy Studies (CEPS).

OECD (2015a). Government at a Glance 2015. Tech. rep. OECD. URL: \url \{http://www . oecd - ilibrary . org / governance / government - at - a - glance - 2015_gov_glance 2015-en\}.

OECD (2015b). Health at a Glance 2015. Tech. rep. OECD. URL: \url \{http://www. oecdilibrary . org / docserver / download $/ 8115071 \mathrm{e} \cdot \mathrm{pdf}$ ? expires $=1456354921 \&$ id=id\& accname=guest \&checksum=2658DB2EC22A461C6ABFD8C1A33175A2\}.

Ortiz-Ospina, Esteban and Max Roser (2020). "Government Spending". In: Our World in Data. https://ourworldindata.org/government-spending.

Ostry, Jonathan D. and Atish R. Ghosh (Dec. 2013). Obstacles to International Policy Coordination, and How to Overcome Them. IMF Staff Discussion Note SDN 13/11. International Monetary Fund. URL: \url\{https://www.imf .org/external/pubs/ft/ $\operatorname{sdn} / 2013 / \operatorname{sdn} 1311 . p d f\}$.

Ott, Ingrid and Susanne Soretz (2010). "Productive Public Input, Integration and Agglomeration". In: Regional Science and Urban Economics 40, pp. 538-549. DOI: 10.1016/j . regsciurbeco.2010.07.001.

Park, Hyun (2006). Expenditure composition and distortionary tax for equitable economic growth. Working Paper 06(165). IMF.

Puga, Diego (2002). "European Regional Policies in Light of Recent Location Theories". In: Journal of Economic Geography 2, pp. 372-406.

Rivera-Batiz, Luis and Paul M. Romer (1991). "Economic Integration and Endogenous Growth". In: The Quarterly Journal of Economics 106, pp. 531-555.

Romer, Paul M. (1986). "Increasing Returns and Long-Run Growth". In: Journal of Political Economy 94, pp. 1002-1037. 
Sala-I-Martin, Xavier (1996a). "Regional Cohesion: Evidence and Theories of Regional Growth and Convergence". In: European Economic Review 40(6), pp. 1325-1352.

Sala-I-Martin, Xavier (1996b). "The Classical Approach to Covergence Analysis". In: The Economic Journal 106, pp. 1019-1036. 


\section{Appendix}

\subsection{Classificatin of functions of government (COFOG): Overview of di- visions and groups}

\begin{tabular}{|c|c|}
\hline Government broad objective & Sub-items \\
\hline General public services & $\begin{array}{l}\text { Executive and legislative organs, financial and fiscal } \\
\text { affairs, external affairs; foreign economic aid; general } \\
\text { services; basic research; R\&D related to general pub- } \\
\text { lic services; general public services n.e.c.; public debt } \\
\text { transactions, transfers of a general character between } \\
\text { different levels of government. }\end{array}$ \\
\hline Defence & $\begin{array}{l}\text { Military defence; civil defence; foreign military aid, } \\
\text { R\&D related to defence; defence n.e.c. }\end{array}$ \\
\hline Public order and safety & $\begin{array}{l}\text { Police services; fire-protection services; law courts; } \\
\text { prisons; R\&D related to public order and safety; pub- } \\
\text { lic order and safety n.e.c. }\end{array}$ \\
\hline Economic affairs & $\begin{array}{l}\text { General economic, commercial and labour affairs; } \\
\text { agriculture, forestry; fishing and hunting; fuel and en- } \\
\text { ergy; mining, manufacturing and construction; trans- } \\
\text { port; communication; other industries, R\&D related } \\
\text { to economic affairs; economic affairs n.e.c. }\end{array}$ \\
\hline Environmental protection & $\begin{array}{l}\text { Waste management; water waste management; pollu- } \\
\text { tion abatement; protection of biodiversity and land- } \\
\text { scape; R\&D related to environmental protection. }\end{array}$ \\
\hline Housing, community amenities & $\begin{array}{l}\text { Housing development; community development; wa- } \\
\text { ter supply; street lighting; R\&D related to housing } \\
\text { and community amenities; housing and community } \\
\text { amenities n.e.c. }\end{array}$ \\
\hline Health & $\begin{array}{l}\text { Medical products, appliances and equipment; outpa- } \\
\text { tient services; hospital services; public health services; } \\
\text { R\&D related to health; health n.e.c. }\end{array}$ \\
\hline Recreation, culture and religion & $\begin{array}{l}\text { Recreational and sporting services; cultural services; } \\
\text { broadcasting and publishing services; religious and } \\
\text { other community services, R\&D related to recreation, } \\
\text { culture and religion; recreation; culture and religion } \\
\text { n.e.c. }\end{array}$ \\
\hline Education & $\begin{array}{l}\text { Pre-primary, primary, secondary and tertiary educa- } \\
\text { tion, post-secondary non-tertiary education, educa- } \\
\text { tion non definable by level, subsidiary services to ed- } \\
\text { ucation, R\&D; n.e.c. }\end{array}$ \\
\hline Social protection & $\begin{array}{l}\text { Sickness and disability; old age; survivors; family and } \\
\text { children; unemployment; housing; R\&D; social pro- } \\
\text { tection and social exclusion n.e.c. }\end{array}$ \\
\hline
\end{tabular}

The Classification of the functions of government, abbreviated as COFOG, was developed in its current version in 1999 by the OECD and published by the United Nations 
Statistical Division as a standard classifying the purposes of government activities. Source: https://ec. europa.eu/eurostat/statistics-explained/index.php?title=Glossary: Classification_of_the_functions_of_government_(COFOG), accessed 10.07.2020.

\subsection{MatrixPlot of $\theta^{s}$}

Note that $\theta^{S}$ unequivocally falls short of unity and even ngeative values of $\theta^{S}$ may be identified. This restricts the reasonable parameter constellations of the bifurcation parameters. Table 1 presents the numerical values on which Figure 14 has been plot.

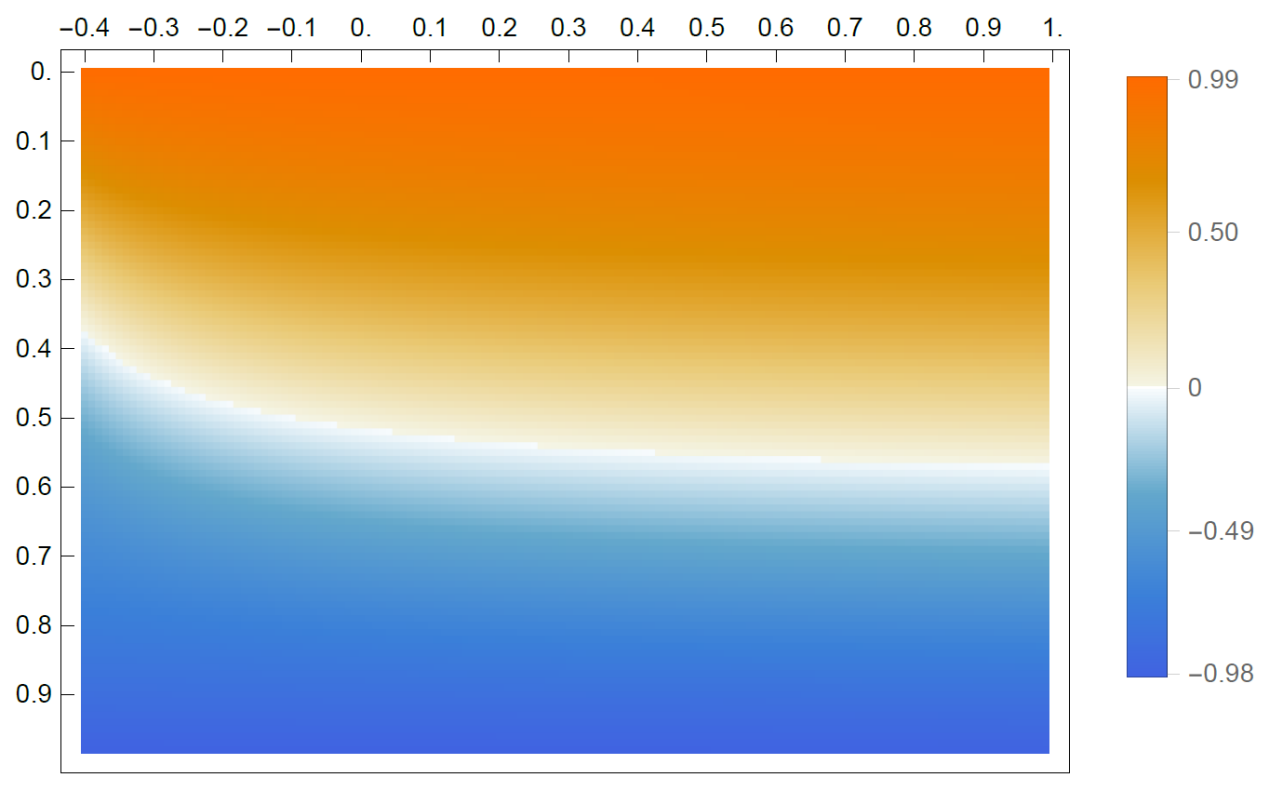

Figure 14: Matrix plot of $\theta^{s}$ based on Table 1 is based; vertical axis: $\beta \in[0,1]$, horizontal axis: $\varepsilon_{A} \in[-0.4,1]$

\subsection{Total effect and partial effects of $d \theta / d k$ for all coordination schemes}

\subsubsection{Full coordination}

Starting point is equation (10). Calculations of the partial effects via application of the implicit function theorem with $T \equiv T_{0}+T_{1}+T_{2}$

$$
T \equiv \underbrace{-\left(\frac{g_{s}+\beta}{1+\beta g_{s}}\right)^{\gamma-1}}_{T_{0}}+\underbrace{\frac{1-\beta k^{\varepsilon_{A}} n^{\varepsilon_{A}-\varepsilon_{R}}}{k^{\varepsilon_{A}} n^{\varepsilon_{A}-\varepsilon_{R}}-\beta}}_{T_{1}} \cdot \underbrace{l^{-\lambda} k^{-\alpha}}_{T_{2}}
$$

from (10). This approach holds analogously for all coordination schemes. The following equation illustrates exemplary how the total effect may be subdivided into partial effects in case of full coordination. 
Table 1: Numerical values based on $\theta^{s}$ from (24) and being displayed in the matrix plot in Figure 14; negative values are replaced by "-"

\begin{tabular}{c|cccccccccc} 
& $\beta=0$. & $\beta=0.1$ & $\beta=0.2$ & $\beta=0.3$ & $\beta=0.4$ & $\beta=0.5$ & $\beta=0.6$ & $\beta=0.7$ & $\beta=0.8$ & $\beta=0.9$ \\
\hline$\epsilon \mathrm{A}=-0.4$ & 0.999 & 0.913 & 0.658 & 0.283 & - & - & - & - & - & - \\
$\epsilon \mathrm{A}=-0.3$ & 1. & 0.948 & 0.785 & 0.501 & 0.147 & - & - & - & - & - \\
$\epsilon \mathrm{A}=-0.2$ & 1. & 0.96 & 0.832 & 0.595 & 0.27 & - & - & - & - & - \\
$\epsilon \mathrm{A}=-0.1$ & 1. & 0.966 & 0.856 & 0.646 & 0.344 & - & - & - & - & - \\
$\epsilon \mathrm{A}=0$. & 1. & 0.97 & 0.871 & 0.679 & 0.394 & 0.052 & - & - & - & - \\
$\epsilon \mathrm{A}=0.1$ & 1. & 0.973 & 0.881 & 0.702 & 0.429 & 0.093 & - & - & - & - \\
$\epsilon \mathrm{A}=0.2$ & 1. & 0.974 & 0.888 & 0.718 & 0.456 & 0.125 & - & - & - & - \\
$\epsilon \mathrm{A}=0.3$ & 1. & 0.976 & 0.894 & 0.731 & 0.476 & 0.15 & - & - & - & - \\
$\epsilon \mathrm{A}=0.4$ & 1. & 0.977 & 0.898 & 0.741 & 0.493 & 0.17 & - & - & - & - \\
$\epsilon \mathrm{A}=0.5$ & 1. & 0.977 & 0.902 & 0.749 & 0.506 & 0.187 & - & - & - & - \\
$\epsilon \mathrm{A}=0.6$ & 1. & 0.978 & 0.904 & 0.756 & 0.517 & 0.202 & - & - & - & - \\
$\epsilon \mathrm{A}=0.7$ & 1. & 0.979 & 0.907 & 0.761 & 0.527 & 0.214 & - & - & - & - \\
$\epsilon \mathrm{A}=0.8$ & 1. & 0.979 & 0.909 & 0.766 & 0.535 & 0.224 & - & - & - & - \\
$\epsilon \mathrm{A}=0.9$ & 1. & 0.98 & 0.91 & 0.77 & 0.542 & 0.234 & - & - & - & -
\end{tabular}

$$
\begin{aligned}
& \frac{d \theta^{*}}{d k}=\underbrace{-\frac{\overbrace{\partial T_{0} / \partial g_{s} \cdot \partial g_{s} / \partial k}^{+}}{\partial T / \partial \theta}}_{\mathrm{SE} ;-}-\underbrace{-\frac{\overbrace{\partial T_{1} / \partial k}^{?} \cdot T_{2}}{\underbrace{\partial T / \partial \theta}_{+}}}_{+} \underbrace{-\frac{T_{1} \cdot \overbrace{\partial T_{2} / \partial k}^{-}}{\underbrace{\partial T / \partial \theta}_{C E ;}}}_{\text {? }} \\
& \frac{d \theta^{*}}{d k}=-\frac{\partial T / \partial k}{\partial T / \partial \theta}
\end{aligned}
$$

calculating the numerator in (36) provides:

$$
\begin{aligned}
& \frac{\partial T}{\partial k}=\underbrace{\frac{\partial T_{0}}{\partial g_{s}} \cdot \frac{\partial g_{s}}{\partial k}}_{+}+\underbrace{\frac{\partial T_{1}}{\partial k}}_{?} \cdot \underbrace{T_{2}}_{+}+\underbrace{T_{1}}_{+} \cdot \underbrace{\frac{\partial T_{2}}{\partial k}}_{-} \\
& \frac{\partial T_{0}}{\partial g_{s}} \frac{\partial g_{s}}{\partial k}=\underbrace{-(\gamma-1)\left(\frac{g_{s}+\beta}{1+\beta g_{s}}\right)^{\gamma} \frac{1-\beta^{2}}{\left(g_{s}+\beta\right)^{2}}}_{\frac{\partial T_{0}}{\partial g_{s}}} \cdot \underbrace{\left(1+\varepsilon_{A}\right) \cdot \frac{g_{s}}{k}}_{\frac{\partial g_{s}}{\partial k}}>0 \\
& \frac{\partial T_{1}}{\partial k}=-\frac{\left(1-\beta^{2}\right) \varepsilon_{A} k^{\varepsilon_{A}-1} n^{\varepsilon_{A}-\varepsilon_{R}}}{\left(k^{\varepsilon_{A}} n^{\varepsilon_{A}-\varepsilon_{R}}-\beta\right)^{2}} \quad \gtrless 0 \quad \Leftrightarrow \quad \varepsilon_{A} \lessgtr 0 \\
& \frac{\partial T_{2}}{\partial k}=-\alpha \cdot l^{-\lambda} k^{-\alpha-1} \quad<0
\end{aligned}
$$


calculating the denominator of (36) gives:

$$
\begin{aligned}
\frac{\partial T}{\partial \theta} & =\frac{\partial T}{\partial g_{s}} \frac{\partial g_{s}}{\partial \theta}=\underbrace{\frac{\partial T_{0}}{\partial g_{s}}}_{\text {von }(38)} \frac{\partial g_{s}}{\partial \theta} \\
& =-(\gamma-1)\left(\frac{g_{s}+\beta}{1+\beta g_{s}}\right)^{\gamma-2} \frac{1-\beta^{2}}{\left(1+\beta g_{s}\right)^{2}} \cdot \frac{g_{s}}{\theta} \quad>0
\end{aligned}
$$

Now allocate the terms to (36) thereby utilizing (37), (41) and (35) to get the negative substitution effect:

$$
-\frac{\partial T_{0} / \partial g_{s} \cdot \partial g_{s} / \partial k}{\partial T_{0} / \partial g_{s} \cdot \partial g_{s} / \partial \theta}=-\left(1+\varepsilon_{A}\right) \frac{\theta}{k}
$$

ambiguous integration effect:

$$
-\frac{\partial T_{1} / \partial k \cdot T_{2}}{\partial T / \partial \theta}=\frac{\left(1+\beta g_{s}\right)^{\gamma}}{\left(g_{s}+\beta\right)^{\gamma-2}} \cdot l^{-\lambda} k^{-\alpha} n^{-1} \cdot \frac{k^{-2}}{\left(k^{\varepsilon_{A}} n^{\varepsilon_{A}-\varepsilon_{R}}-\beta\right)^{2}} \cdot \frac{\varepsilon_{A}}{1-\gamma} \gtrless 0 \Leftrightarrow \quad \varepsilon_{A} \gtrless 0
$$

positive complementarity effect:

$-\frac{T_{1} \cdot \partial T_{2} / \partial k}{\partial T / \partial \theta}=\frac{\left(1+\beta g_{s}\right)^{\gamma}}{\left(g_{s}+\beta\right)^{\gamma-2}} \cdot l^{-\lambda} k^{-\alpha-1} \cdot \frac{\left(1-\beta k^{\varepsilon_{A}} n^{\varepsilon_{A}-\varepsilon_{R}}\right) k^{-2}}{\left(k^{\varepsilon_{A}} n^{\varepsilon_{A}-\varepsilon_{R}}-\beta\right) k^{1+\varepsilon_{A}} n^{\varepsilon_{A}-\varepsilon_{R}}} \cdot \frac{\alpha}{1-\gamma} \cdot \frac{1}{1-\beta^{2}} \quad>0$

\subsubsection{No coordination: Cournot}

Equation (17) serves as a reference.

$$
T=\underbrace{-\left(\frac{g_{s}+\beta}{1+\beta g_{s}}\right)^{\gamma-1}}_{T_{0}}+\underbrace{\frac{1}{k^{\varepsilon_{A}} n^{\varepsilon_{A}-\varepsilon_{R}}}}_{T_{1}} \cdot \underbrace{l^{-\lambda} k^{-\alpha}}_{T_{2}}
$$

negative substitution effect: is identical to (42)

\section{ambiguous integration effect:}

$$
\begin{aligned}
\frac{\partial T_{1}}{\partial k} & =-\varepsilon_{A} k^{-\varepsilon_{A}-1} n^{-\varepsilon_{A}+\varepsilon_{R}} \\
\frac{\partial T}{\partial \theta}=\frac{\partial T_{0}}{\partial g_{s}} \cdot \frac{\partial g_{s}}{\partial \theta} & =\text { identical to }(41)
\end{aligned}
$$

The direction is identical to IE planner (43) while the effect is reinforced by the last term.

$$
-\frac{\partial T_{1} / \partial k \cdot T_{2}}{\partial T / \partial \theta}=\frac{\left(1+\beta g_{s}\right)^{\gamma}}{\left(g_{s}+\beta\right)^{\gamma-2}} \cdot l^{-\lambda} k^{-\alpha} n^{-1} \cdot \frac{1}{\left(k^{1+\varepsilon_{A}} n^{\varepsilon_{A}-\varepsilon_{R}}\right)^{2}} \cdot \frac{\varepsilon_{A}}{1-\gamma} \cdot \frac{1}{1-\beta^{2}} \gtrless 0 \Longleftrightarrow \quad \varepsilon_{A} \gtrless 0
$$


positive complementarity effect: $\frac{\partial T_{2}}{\partial k}=-\alpha l^{-\lambda} k^{-\alpha-1}$ remains unchanged. CE Cournot is identical to CE planner (44)

$$
-\frac{T_{1} \partial T_{2} / \partial k}{\partial T / \partial \theta}=\frac{\left(1+\beta g_{s}\right)^{\gamma}}{\left(g_{s}+\beta\right)^{\gamma-2}} \cdot l^{-\lambda} k^{-\alpha} n^{-1} \cdot \frac{1}{\left(k^{1+\varepsilon_{A}} n^{\varepsilon_{A}-\varepsilon_{R}}\right)^{2}} \cdot \frac{\alpha}{1-\gamma} \cdot \frac{1}{1-\beta^{2}} \quad>0
$$

\subsubsection{Partial coordination: Stackelberg}

Starting from (23) (recall: compared to Cournot and planner setting, valid parameter domains for $\varepsilon_{A}$ and $\beta$ are restricted)

$$
T=-\left(\frac{g_{s}+\beta}{1+\beta g_{s}}\right)^{\gamma-1}+\frac{1}{\left(1-\beta^{2}\right) k^{\varepsilon_{A}} n^{\varepsilon_{A}-\varepsilon_{R}}} l^{-\lambda} k^{-\alpha}
$$

negative substitution effect: is identical to planner (42) but now utilizing $\theta^{S}$ from (24)

$$
-\frac{\partial T_{1} / \partial g_{s} \cdot \partial g_{s} / \partial k}{\partial T_{0} / \partial g_{s} \cdot \partial g_{s} / \partial \theta}=-\left(1+\varepsilon_{A}\right) \frac{\theta}{k}
$$

ambiguous integration effect: analogous to Cournot but reinforced via scaling factor, and utilizing $\theta^{S}$ from (24)

$$
-\frac{\partial T_{1} / \partial k \cdot T_{2}}{\partial T / \partial \theta}=\frac{1}{1-\beta^{2}} \cdot(48)
$$

positive complementarity effect: analogous to Cournot but reinforced via scaling factor, and utilizing $\theta^{S}$ from (24)

$$
-\frac{T_{1} \partial T_{2} / \partial k}{\partial T / \partial \theta}=\frac{1}{1-\beta^{2}}
$$

Thus, the strength of CE and IE are always stronger in case of partial coordination (Stackelberg) compared to no coordianation (Cournot) while the effects' direction is identical. 


\subsubsection{Effect of integration and scale on the sign of the partial effects}

\begin{tabular}{|c|c|c|c|c|c|c|}
\hline & \multicolumn{2}{|l|}{ Planner } & \multicolumn{2}{|l|}{ Cournot } & \multicolumn{2}{|c|}{ Stackelberg } \\
\hline & $\frac{d \frac{d \theta}{d k}}{d \beta}$ & $\frac{d \frac{d \theta}{d k}}{d \varepsilon_{A}}$ & $\frac{d \frac{d \theta}{d k}}{d \beta}$ & $\frac{d \frac{d \theta}{d k}}{d \varepsilon_{A}}$ & $\frac{d \frac{d \theta}{d k}}{d \beta}$ & $\frac{d \frac{d \theta}{d \varepsilon_{A}}}{d \varepsilon^{2}}$ \\
\hline IE & $\lessgtr 0 \Leftrightarrow \varepsilon_{A} \lessgtr 0$ & $>0$ & $\lessgtr 0 \Leftrightarrow \varepsilon_{A} \lessgtr 0$ & $>0$ & $\lessgtr 0 \Leftrightarrow \varepsilon_{A} \lessgtr 0$ & $>0$ \\
\hline SE & 0 & $<0$ & 0 & $<0$ & $<0$ & $<0$ \\
\hline $\mathrm{CE}$ & $>0$ & $<0$ & $>0$ & $<0$ & $>0$ & $<0$ \\
\hline TE & $\lessgtr 0$ & $>0$ & $>0$ & $>0$ & $>0$ & $>0$ \\
\hline
\end{tabular}

Table 2: overview on sign of partial effects depending upon integration and scale if $n=l=k=1$ and for $\theta^{*}=\theta^{a}=1, \theta^{S}<1$ (compare equations (11), (18) and (24)).

\subsection{Underlying growth model}

Preferences of the identical and infinitely living household include maximizing lifetime utility out of consumption according to ${ }^{30}$

$$
U_{i}=\int_{0}^{\infty} \frac{\sigma}{\sigma-1} C_{i}(t)^{\frac{\sigma-1}{\sigma}} e^{-\rho t} d t \quad \rho>0, \quad 0<\sigma<1
$$

The subjective discount rate is denoted by $\rho, \sigma$ is the elasticity of intertemporal substitution, and $C_{i}(t)$ describes consumption in region $i$.

Households save by accumulating a risk free asset. The asset value equals the value of the stock of capital at any point in time; hence, the asset value in region $i$ at time $t$ equals $V_{i}(t) \equiv q_{1}(t) K_{1 i}(t)+q_{2}(t) K_{2 i}(t)$, where $q_{i}$ denotes the stock price of capital installed in region $i$. The immobile workers earn labor income as well as capital income from investment in both regions. Wages in region $i$ are denoted by $w_{i}(t)$. The total income in region $i$ evolves according to

$$
\dot{V}_{i}(t)=w_{i}(t) L_{i}(t)+(r(t)-\delta) V_{i}(t)-C_{i}(t)-T_{i}(t)
$$

with $r(t)$ denoting the interest rate determined in capital market equilibrium, $\delta$ as the constant depreciation rate of private capital and $T_{i}(t)$ a lump-sum tax that is used to finance the provision of the public input. To fully describe the optimization problem, the transversality conditions

$$
\lim _{t \rightarrow \infty} K_{1 i}(t) \xi_{i}(t)=0 \quad \lim _{t \rightarrow \infty} K_{2 i}(t) \xi_{i}(t)=0
$$

have to be met, where $\xi_{i}$ denotes the shadow value of capital in region $i$. Maximizing (54) subject to the accumulation constraint (55) leads to the Hamiltonian

$$
\mathcal{H}_{\rangle}=\frac{\sigma}{\sigma-1} C_{i}(t)^{\frac{\sigma-1}{\sigma}} e^{-\rho t}+\xi_{i}\left(w_{i}(t) L_{i}(t)+(r(t)-\delta) V_{i}(t)-C_{i}(t)-T_{i}(t)\right)
$$

\footnotetext{
${ }^{30}$ The setup of the model mainly borrows from Ott and Soretz (2010).
} 
with optimal consumption described by the necessary conditions

$$
\begin{aligned}
& \frac{\partial \mathcal{H}\rangle}{\partial C_{i}}=C_{i}^{-\frac{1}{\sigma}} e^{-\rho t}-\xi_{i} \stackrel{!}{=} 0 \\
& \frac{\partial \mathcal{H}\rangle}{\partial V_{i}}=\xi_{i}(r(t)-\delta) \stackrel{!}{=}-\dot{\xi}_{i}
\end{aligned}
$$

and leading to the well known growth rate of consumption as ${ }^{31}$

$$
\frac{\dot{C}_{i}}{C_{i}}=\sigma(r-\delta-\rho) \equiv \varphi
$$

Households in both regions realize identical consumption growth, a direct consequence from homothetic preferences together with equal investment opportunities. Moreover, due to constant average returns of capital, the consumption-wealth ratio is constant and hence the growth rates of consumption, capital and income coincide. An increase in capital return, $r$, will increase the growth rate due to strengthened incentives for capital accumulation. In contrast, an income tax would reduce net capital return and therefore decrease the growth rate. It is well known from growth literature that a lump-sum tax $T_{i}(t)$ is growth neutral, since it does not influence capital return.

\footnotetext{
${ }^{31}$ Here time indices have been suppressed.
} 


\section{Working Paper Series in Economics}

recent issues

No. 142 Ingrid Ott and Susanne Soretz: Institutional design and spatial (in)equality - the Janus face of economic integration, August 2020

No. 141 Laura Reh, Fabian Krüger and Roman Liesenfeld: Predicting the global minimum variance portfolio, July 2020

No. 140 Marta Serra Garcia and Nora Szech: Understanding demand for COVID-19 antibody testing, May 2020

No. 139 Fabian Krüger and Lora Pavlova: Quantifying subjective uncertainty in survey expectations, March 2020

No. 138 Michael Müller and Clemens Puppe: Strategy-proofness and responsiveness imply minimal participation, January 2020

No. 137 Andranik S. Tangian: Tackling the Bundestag growth by introducing fraction-valued votes, October 2019

No. 136 Susanne Fuchs-Seliger: Structures of rational behavior in economics, September 2019

No. 135 Cornelia Gremm, David Bälz, Chris Corbo and Kay Mitusch: Intermodal competition between intercity buses and trains - A theoretical model, September 2019

No. 134 Marta Serra-Garcia and Nora Szech: The (in)elasticity of moral ignorance, August 2019

No. 133 Andranik S. Tangian: Composite indicators for computer-aided collective bargaining, July 2019

No. 132 Andranik S. Tangian: Combining the third vote with traditional elections, May 2019 